\title{
Seasonally-dependent impact of easterly wind bursts on the development of El Niño events
}

\author{
Hanjie Fan ${ }^{1} \cdot$ Bohua Huang ${ }^{2} \cdot$ Song Yang ${ }^{1,3,4} \cdot$ Zhenning Li $^{1} \cdot$ Kaiqiang Deng ${ }^{1}$
}

Received: 11 September 2018 / Accepted: 14 February 2019 / Published online: 5 March 2019

(c) The Author(s) 2019

\begin{abstract}
Westerly wind bursts play an important role in the development of El Niño-Southern Oscillation (ENSO) events. However, the impact of easterly wind bursts (EWBs) on the development of ENSO is still unclear. In particular, a series of strong EWBs in the summer of 2014 aroused arguments about their importance in suppressing the potential warming in the summer. In this study, we conduct a series of sensitivity experiments using the fully-coupled NCAR Community Earth System Model with prescribed strong EWBs to distinguish their impact on the development of the model El Niño events, as well as the seasonality of the potential impact. Model results indicate that wintertime warming is significantly suppressed by the EWBs in summer due to the strongest ocean-atmosphere interaction associated with the most unstable background coupled system. With stronger anomalous zonal SST gradient and relatively more stable background state, the EWB-induced cooling in autumn is smaller than the cooling induced by the summertime EWBs. In spring when the ocean-atmosphere interaction is relatively weaker, the impact of EWBs depends on the EWB-forced shift of the eastern edge of warm pool (EEWP), which is critical for the establishment of positive Bjerknes feedback. A mixed layer heat budget analysis further suggests that the seasonally-dependent impact of EWBs is mainly controlled by the zonal advective feedback process associated with the subsequent ocean-atmosphere interaction and to some extent related to the thermocline feedback as well. This study demonstrates that EWBs increase the uncertainty of the prediction of ENSO initialized in boreal spring and early summer even if the ocean subsurface precursors are strong.
\end{abstract}

Keywords Easterly wind burst $\cdot$ Bjerknes feedback $\cdot$ Seasonality $\cdot$ Zonal advective feedback

\section{Introduction}

It is well known that the El Niño-Southern Oscillation (ENSO) is the most significant interannual variations in the tropics with great influences on global weather and climate (Wang et al. 2000; Alexander el al. 2002; Yang et al.

Song Yang

yangsong3@mail.sysu.edu.cn

1 School of Atmospheric Sciences, Sun Yat-sen University, 135 West Xingang Road, Guangzhou 510275, China

2 Department of Atmospheric, Oceanic, and Earth Sciences and Center for Ocean-Land-Atmosphere Studies, George Mason University, Fairfax, VA, USA

3 Guangdong Province Key Laboratory for Climate Change and Natural Disaster Studies, Sun Yat-sen University, Guangzhou, China

4 Southern Laboratory of Ocean Science and Engineering, Zhuhai, Guangdong, China
2018). The growth of ENSO anomalies is associated with an intense ocean-atmosphere feedback among the sea surface temperature (SST), surface zonal winds and zonal slope of the thermocline in the equatorial Pacific, i.e. the Bjerknes feedback (e.g., Bjerknes 1969; Zebiak and Cane 1987). The accumulation and depletion of ocean heat content (HC) in the equatorial Pacific plays a critical role in sustaining the ENSO cycle (Wyrtki 1985; Jin 1997; Meinen and McPhaden 2000). Since the HC anomalies provide preconditions for the occurrence of major ENSO events (El Niños and La Niñas), they offer the ocean "memory" of ENSO predictability on seasonal-to-interannual time scales (e.g., Cane et al. 1986). However, the HC state may not be a sufficient precursor for ENSO occurrence on seasonal time scale. Even with promising $\mathrm{HC}$ precursors, it is still challenging to predict ENSO events in seasonal forecast (e.g., predicting the ENSO status for the upcoming fall and winter during spring and early summer), although the expected ENSO phase would eventually occur. It is also generally agreed that the initiation 
and development of an ENSO event is closely related to the high-frequency zonal wind variations over the equatorial Pacific (Vecchi and Harrison 2000; Mcphaden et al. 2006; Fedorov and Philander 2001; Boulanger et al. 2004). Among the large amount of literature, the role of the westerly wind bursts (WWBs) in triggering El Niño events has long been recognized and widely studied (Vecchi and Harrison 2000; Fedorov 2002; Lengaigne et al. 2004; Gebbie et al. 2007; Chen et al. 2015; Fedorov et al. 2015). In contrast, the easterly wind bursts (EWBs) are nearly out of the spotlight until recently (e.g., Hu and Fedorov 2016, 2017). To some extent, the different treatment is understandable because the causes and relationship of ENSO with EWBs have yet to be fully demonstrated in comparison with the WWBs (e.g. Puy et al. 2016a, b; Chiodi and Harrison 2014). Recent studies suggest that the impact of EWBs on ENSO should not be overlooked. For instance, utilizing a global ocean general circulation model (OGCM), Chiodi and Harrison (2014) argued that, as the counterpart to WWBs in El Niño, the EWBs could make an important contribution to both the onset and the growth of La Niña events. On the other hand, the influence of the EWBs (WWBs) on the evolution of El Niño (La Niña) events has not been widely explored.

The recent event of warming-stalling easterly wind anomaly in the summer of 2014 demonstrated the importance of EWBs in this aspect (Hu and Fedorov 2016). In early 2014, the $\mathrm{HC}$ in the tropical Pacific seemed to be ripe for a warm event. Moreover, a series of WWBs occurred from January to April (Fig. 1c), triggering strong downwelling Kelvin waves propagating to the eastern Pacific (Fig. 1d) and transporting warm water eastward from the warm pool (Fig. 1e). As a result, warm SST anomalies (SSTAs) in the central and eastern Pacific increased rapidly in March and April (Fig. 2a, b). This situation bears noticeable resemblance to that of early 1997, when the strongest El Niño in the instrumental record by then had developed later that year. This feature lead to the expectation that an extreme El Niño event of similar scale might develop in 2014. Many climate models predicted a major El Niño to develop in 2014 and estimated that the SSTAs in the equatorial central and eastern Pacific would exceed $2{ }^{\circ} \mathrm{C}$ in the coming winter. Observationally, however, the rapid warming did not continue when it came to summer (Fig. 1a, b). Instead, the SST tendencies turned negative in June and July (Fig. 2c, d). Although a mild warming tendency resumed later that year, the moderate warm SST anomalies in the equatorial Pacific only reached the level of a marginal central Pacific El Niño by the end of the year (Fig. 1a, b). However, it is noticeable that an extreme El Niño event did occur 1 year later in 2015-16. It is argued that the warm conditions in the equatorial Pacific at the end of 2014 contributed to the 2015-16 El Niño for reaching its extremity (Zhang and Gao 2017; Hu and Fedorov 2017; Santoso et al. 2017). One may argue that the tropical Pacific
HC provided a favorable condition for a major warming but other factors obstructed this potential warm in 2014.

The unusual evolution in 2014 soon drew a lot of attention on the reasons for the failed warming. A few studies propose that the unusual warming over the eastern North Pacific could be responsible for hindering the 2014 potential warming (e.g., Wu et al. 2018). Others suggest that the persistent cold SST anomalies in the southeastern Pacific generated the tendency of easterly wind anomalies over the equatorial ocean (e.g., Zhu et al. 2016; Ineson et al. 2018). However, most investigations emphasize the effect of the high-frequency wind variability in 2014 as the key element. Nevertheless, different opinions have been presented about the importance of wind variability. Some emphasize that the easterly wind event in June possibly related to extratropical activity had prevented the early warming from developing to an El Niño (Min et al. 2015; Hu and Fedorov 2016). Others (e.g. Menkes et al. 2014), however, suggest that the lack of WWBs from April to June caused the decreased warm SSTAs in the following months. Puy et al. (2017) also demonstrated that the weak amplitude of El Niño in 2014 could be explained by the early termination of WWB events without considering EWB events. Forcing an OGCM with surface wind stress, Chiodi and Harrison (2017) showed that, with no wind stress anomaly prescribed after April, the model SSTAs rather accurately track the observed summertime Niño-3.4 SST decrease, reaching $0{ }^{\circ} \mathrm{C}$ in August as observed. Their results imply that an excessive easterly wind stress over summer is unnecessary for the springtime El Niño development to reverse the course midyear. However, since the strong EWB in 2014 appears to be unprecedented (Hu and Fedorov 2017), one may still raise the question on whether the EWBs are important in suppressing the development of the El Niño event, with or without the preceding WWBs.

A further question is whether the timing of the EWBs plays a significant role. The fact that the strong EWB occurred in June of 2014 seemed to be critical to the subsequent oceanic evolution in the tropical Pacific. Previous works have pointed out that the strength of air-sea coupling is seasonally dependent (Chen et al. 1997; Tziperman et al. 1997; Xue et al. 1997; Zhu et al. 2015). Clarke (2014) suggested that the ENSO anomalies were usually strong enough by July to sustain external perturbations and thus became more predictable afterward. Therefore, we would like to pose our second question about how the potential impact of EWBs may vary in different seasons of their occurrences. In posing this question, we recognize that, unlike WWBs, the seasonality of EWBs has yet to be fully documented. We also notice that the forcing by random westerly wind anomalies in late boreal summer is still critical in determining the amplitude of the 1982-1983 strong El Niño event (Takahashi and Dewitte 2016). However, the EWB influence 

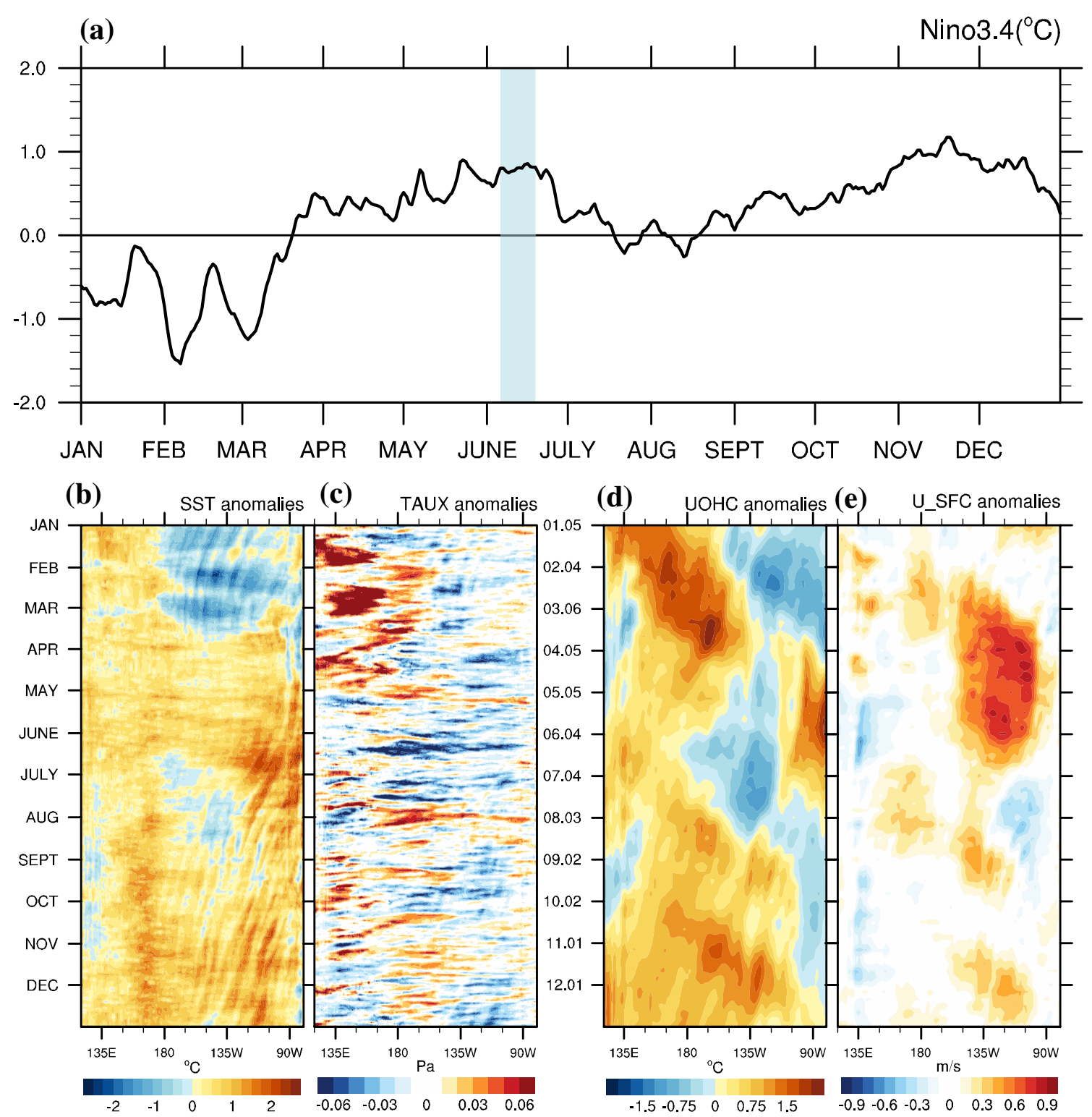

Fig. 1 a Time series of the daily Niño3.4 index $\left({ }^{\circ} \mathrm{C}\right)$ in 2014 . The blue shading bar indicates the period over which unpredicted strong easterly anomalies occurred during the development of equatorial Pacific warming. b-e Time-longitude section of the daily anomalies

at this stage may not be symmetrical to the WWB effect because of nonlinearity of the Bjerknes feedback (Dommenget et al. 2013). Nevertheless, it is deserved to figure out if the impact of EWBs possesses a seasonal dependence as the WWB impact does.

Finally, we would like to consider the EWA effect in the context of oceanic HC preconditions. As discussed earlier, many studies have demonstrated the importance of a "recharged" ocean state in major El Niño events (e.g., Jin 1997). Previous studies have also pointed out that oceanic background conditions can influence the response to zonal wind variations (Schopf and Harrison 1983; Harrison and of SST $\left({ }^{\circ} \mathrm{C}\right)$, zonal wind stress $(\mathrm{Pa})$, and pentad anomalies of upper ocean heat content $\left({ }^{\circ} \mathrm{C}\right)$, zonal surface oceanic current $(\mathrm{m} / \mathrm{s})$ in the equatorial Pacific $\left(5^{\circ} \mathrm{S}-5^{\circ} \mathrm{N}\right)$

Schopf 1984; Busalacchi and Cane 1988; Dewitte et al. 2008). Then, our question is how effectively EWBs affect the ENSO predictability associated with the oceanic memory. To distinguish the impacts of the EWBs in these aspects, we revisit the observed EWB in the unpredicted tropical Pacific evolution in 2014 and conduct a series of sensitivity experiments with the same EWB introduced into the coupled NCAR Community Earth System Model (CESM). These runs are designed as ensemble predictability experiments to several selected El Niño events produced by a CESM long simulation. Our purpose is to (1) isolate the EWB influence from the WWB impact, (2) examine the seasonal 


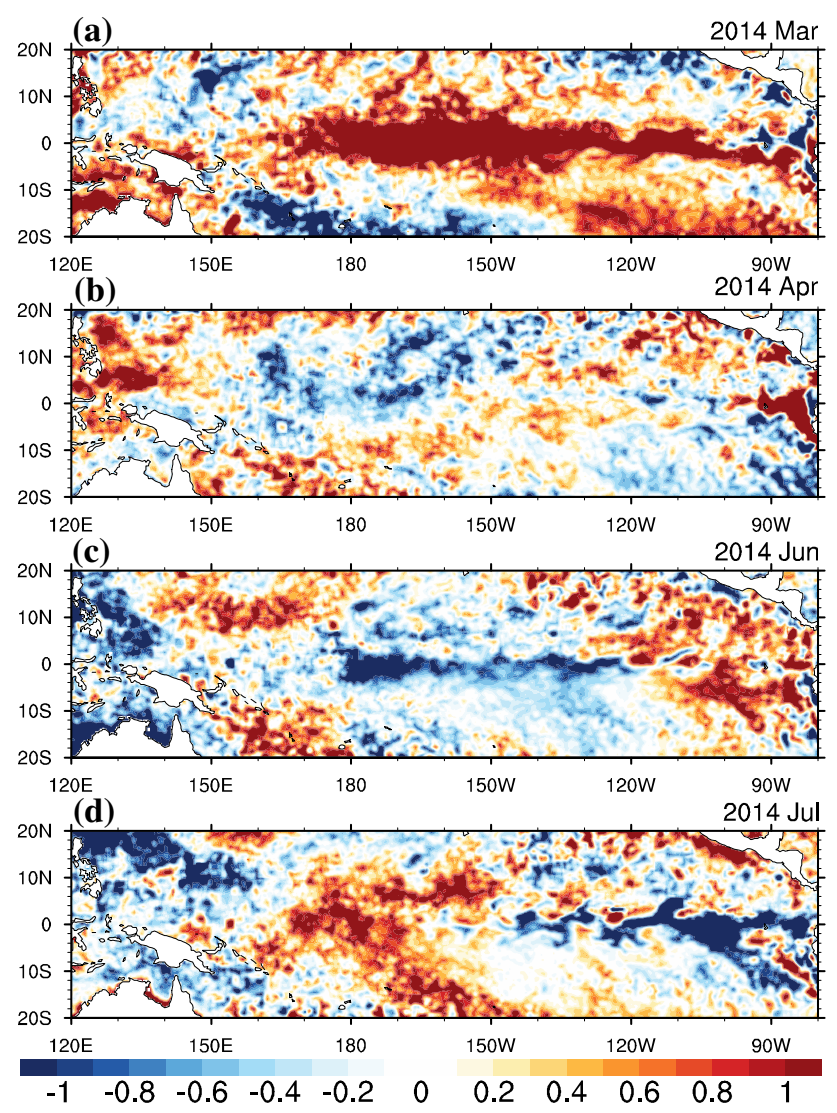

Fig. 2 Time-accumulated surface temperature $\left({ }^{\circ} \mathrm{C}\right)$ change in a March, b April, c June, and d July 2014

dependence of the model response, and (3) test the effectiveness of WEA forcing in El Niño events with different HC preconditioning.

This paper is organized as follows. Section 2 describes the data sets, methods, and model experiments. Section 3 shows how well the model can "predict" the cases with different oceanic memories. In Sect. 4, we discuss the key factors that account for the seasonally-dependent impact of EWBs with model results. Last, a summary and a discussion are given in Sect. 5.

\section{Data and methods}

\subsection{Data sets}

The observed SST data used in this study is the NOAA Optimum Interpolation SSTv2 daily analysis with a resolution of $0.25^{\circ} \times 0.25^{\circ}$ (Reynolds et al. 2007) provided by the NOAA Earth System-Research Laboratory Physical Sciences Division (Boulder, Colorado), and available at https://www.esrl. noaa.gov/psd/. Surface zonal wind stress is from the NOAA National Climate Data Center, calculated based on the bulk formula (Chiodi and Harrison 2017) with daily mean blended sea winds (Zhang et al. 2006) on a global $0.25^{\circ}$ grid. The pentad oceanic reanalysis data including ocean currents and temperature (Behringer and Xue 2004), as well as the pentad mixed layer heat budget terms (Huang et al. 2010), are obtained from the NCEP Global Ocean Data Assimilation System reanalysis (GODAS) with a $1^{\circ} \times 0.33^{\circ}$ horizontal resolution and 40 vertical levels. The upper ocean $\mathrm{HC}$ is calculated with the temperature averaged from the surface to $300 \mathrm{~m}$. The anomalies are computed as the departure from climatological annual cycle of 1981-2010.

\subsection{Model experiments}

The sensitivity numerical experiments are conducted with the coupled earth system model NCAR CESM V1.2.2. The ocean component, Parallel Ocean Program version 2 (POP2), has a horizonal resolution of approximately $1^{\circ}$ on tri-polar grid and a maximum depth of 5375 meters vertically divided into 60 levels. The spatial resolution of the atmospheric component, Version 5.0 of the Community Atmosphere Model (CAM5), is $1.9 \times 2.5$, approximately $2^{\circ} \times 2^{\circ}$. ENSO in the CESM exhibits spatial and temporal characteristics comparable to observations, though with some biases, such as an overestimation of the SST variability in the central-eastern Pacific (Deser et al. 2012; Capotondi 2013; Larson and Kirtman 2013).

After a 250-years spin-up under the green house gas forcing fixed at the levels of year 2000, we integrated the model for additional 50 years to obtain the climatological state and provide samples of typical strong, moderate, and weak El Niño events to be used in our case analysis. Three cases, in model years 257, 282, and 295, were selected according to their evolutions of daily Niño3.4 index and the January mean upper ocean $\mathrm{HC}$ in the equatorial western Pacific (Fig. 3). Case 282 (red line in Fig. 3b) is a strong El Niño event with large amplitude warming exceeding $2.3^{\circ} \mathrm{C}$. Case 257 (orange line in Fig. 3b) develops into a moderate warming case by the end of the year. Case 295 (green line in Fig. 3b) is a weak warm case with smaller initial HC. To exclude the situation that these warm events are totally noise-driven and have little intrinsic predictability, a set of predictability runs (referred to as "PRED" hereafter) with ten ensemble members were performed for each of the selected cases, which are initialized with a small random perturbation applied to the temperature at the upper-level atmospheric initial conditions taken from the restart files of the long simulation. Each predictability run is integrated for 1 year, starting from 1 January.

These three sets of PRED runs serve as the baseline runs to demonstrate the impacts of EWBs. We take the EWBs in summer 2014 as the forcing to conduct a set of sensitivity experiments to the PRED runs. To introduce the impact of EWBs into CESM, we replace the zonal wind 

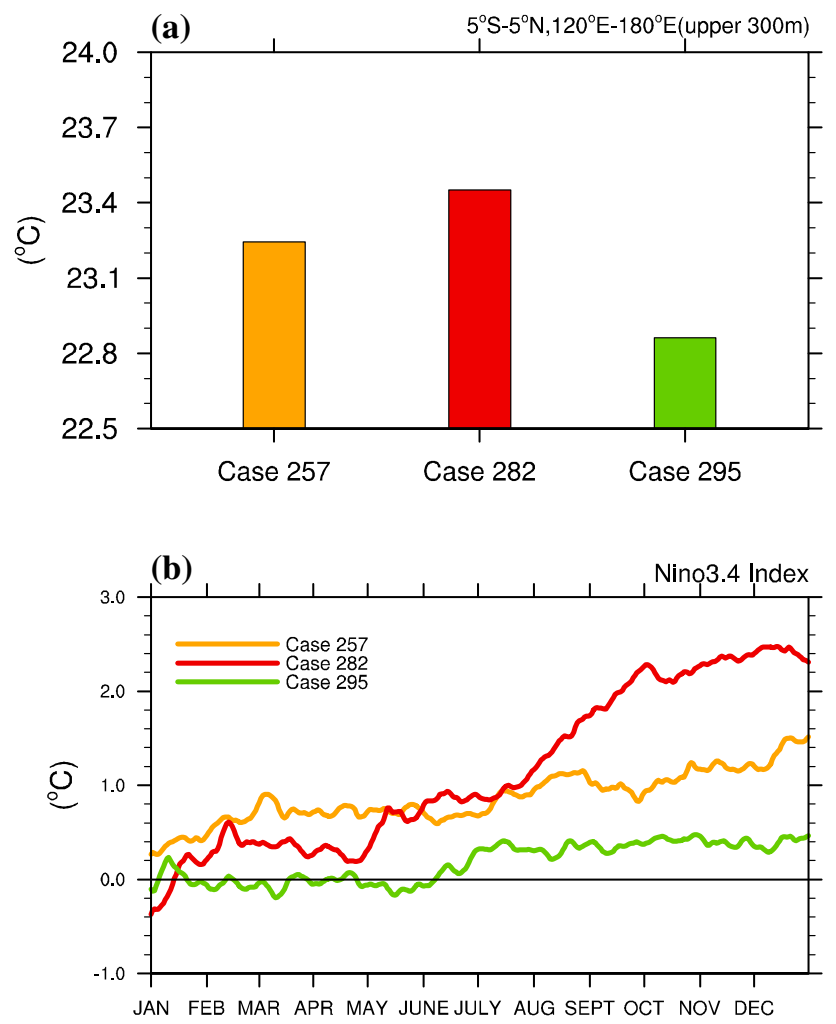

Fig. 3 a Upper ocean heat content $\left({ }^{\circ} \mathrm{C}\right)$ in the equatorial western Pacific region $\left(5^{\circ} \mathrm{S}-5^{\circ} \mathrm{N}, 120^{\circ} \mathrm{E}-180^{\circ} \mathrm{E}\right)$ of three different cases in the CESM. b Time series of the daily Niño3. 4 index $\left({ }^{\circ} \mathrm{C}\right)$ of the above three cases: case 282 (red line) was a strong El Niño case with large amplitude warming exceeding $2.3{ }^{\circ} \mathrm{C}$, case 257 (orange line) developed into a moderate warming case by the end of the year, and case 295 (green line) was a nearly neutral but still warm case

stress produced by the coupled model with the observed anomalies plus the model climatology to force the ocean component in specified time period and spatial area. The EWBs are introduced into the model in the same area as they were observed in 2014 , i.e. $5^{\circ} \mathrm{S}-5^{\circ} \mathrm{N} / 140^{\circ} \mathrm{E}-80^{\circ} \mathrm{W}$. In order to examine the seasonality of their possible impact, we perform three groups of sensitivity experiments with the EWB forcing from the 6th to the 19th of March, June, and September of the three cases, respectively. The sensitivity runs have the same initial states as those in the PRED runs with the same number of the ensemble members and are integrated for the same length. The only difference between the two sets of experiments is the added EWB forcing in the sensitivity experiments. These three groups of sensitivity experiments are named as "EWB3", "EWB6", and "EWB9", respectively, where numeric stands for the month that the EWB forcing is prescribed. For convenience, the main features of the sensitivity experiments are depicted by a schematic in Fig. 4.

\subsection{Decompositions of heat budgets}

To diagnose the dynamic and thermodynamic processes of SST response to EWBs, we apply a mixed layer heat budget analysis to the difference between the EWB and PRED runs. Following Zhu and Kumar (2018), the budget difference equation can be written as:

$\frac{\partial T^{\prime}}{\partial t}=-(V \cdot \nabla T)^{\prime}+\frac{Q_{n e t}^{\prime}}{\rho_{0} C_{p} H}+R$

where $\mathrm{T}$ denotes the mixed layer temperature, $\mathrm{V}$ the threedimensional ocean current, and $\nabla$ the gradient operator. $Q_{n e t}$ is the net surface heat flux into the ocean, including net downward shortwave and longwave radiation, and surface sensible and latent heat fluxes. $\rho_{0}$ and $C_{p}$ are density and specific heat of water, respectively, taken as constants here. $R$ is the residual term. Moreover, we assume that the mixed layer depth $(\mathrm{H})$ is constant at $50 \mathrm{~m}$. The advection term $-(V \cdot \nabla T)^{\prime}$ in Eq. (1) can be further decomposed into six parts:

$$
\underbrace{-u^{\prime} \frac{\partial \bar{T}}{\partial x}}_{\mathrm{ZA}}-\underbrace{v^{\prime} \frac{\partial \bar{T}}{\partial y}}_{\mathrm{VA}}-\underbrace{w^{\prime} \frac{\partial \bar{T}}{\partial z}}_{\mathrm{EK}}-\underbrace{\left(\bar{u} \frac{\partial T^{\prime}}{\partial x}+\bar{v} \frac{\partial T^{\prime}}{\partial y}\right)}_{\mathrm{MA}}-\underbrace{\bar{w} \frac{\partial T^{\prime}}{\partial z}}_{\mathrm{TH}}-\underbrace{\left(u^{\prime} \frac{\partial T^{\prime}}{\partial x}+v^{\prime} \frac{\partial T^{\prime}}{\partial y}+w^{\prime} \frac{\partial T^{\prime}}{\partial z}\right.}_{\mathrm{NDH}})
$$

Fig. 4 Schematic depicting the model framework of the EWB experiment

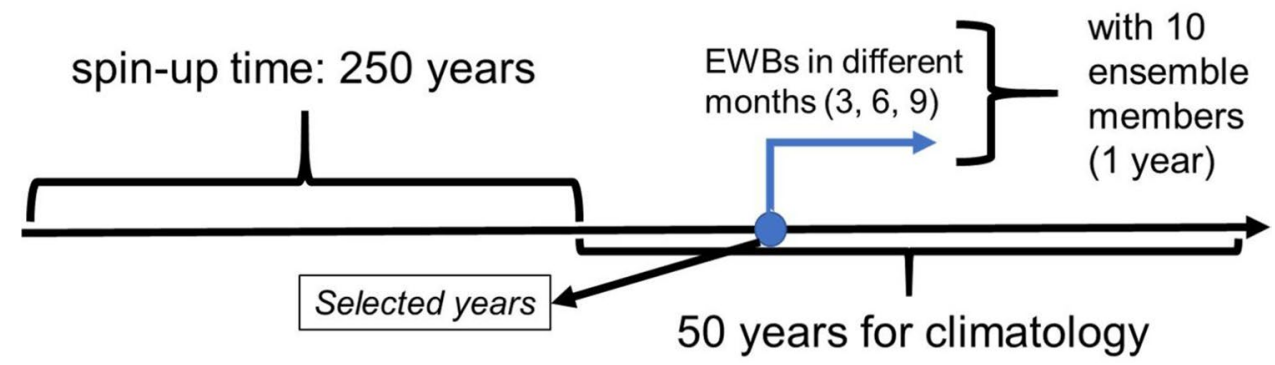


The first three terms present the advection of anomalous current of the mean temperature, which can generate the zonal advective feedback (ZA), the meridional advective feedback (VA), and the Ekman pumping feedback (EK) respectively in a coupled system. The next term is the mean current advection of the temperature anomaly (MA). The mean vertical advection of temperature anomaly can be associated with the thermocline feedback (TH) in a coupled system. The last term represents nonlinear advection, usually referred to as nonlinear dynamical heating (NDH). In Eqs. (1) and (2), the overbar denotes the variables in PRED and the prime is the ensemble mean difference between EWBs and PRED.
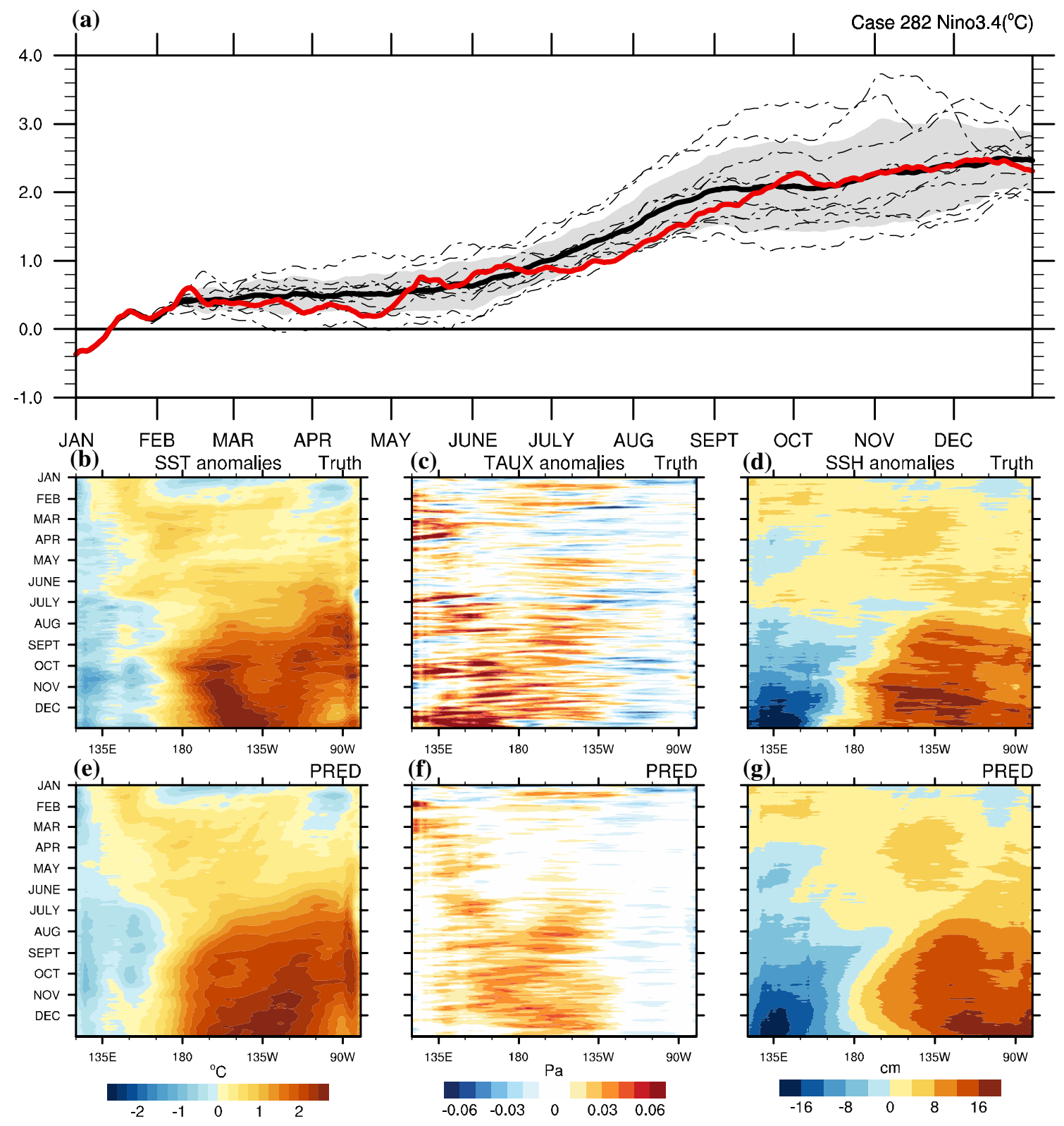

Fig. 5 a Time series of daily Niño3.4 index $\left({ }^{\circ} \mathrm{C}\right)$ in case 282 and the ensemble members. The red line is same as the one in Fig. $2 \mathrm{~b}$, showing the evolution of the "truth", and the thin broken lines show the results of the ten ensemble members. The ensemble mean is shown by the black solid line and the grey shading area shows the standard deviation among the ten members. b-d Time-longitude sections of the equatorial Pacific $\left(5^{\circ} \mathrm{S}-5^{\circ} \mathrm{N}\right)$ daily anomalies of SST $\left({ }^{\circ} \mathrm{C}\right)$, zonal wind stress $(\mathrm{Pa})$, and sea surface height $(\mathrm{cm})$ of the "truth" in case 282. e-g Same as b-d but for the PRED 

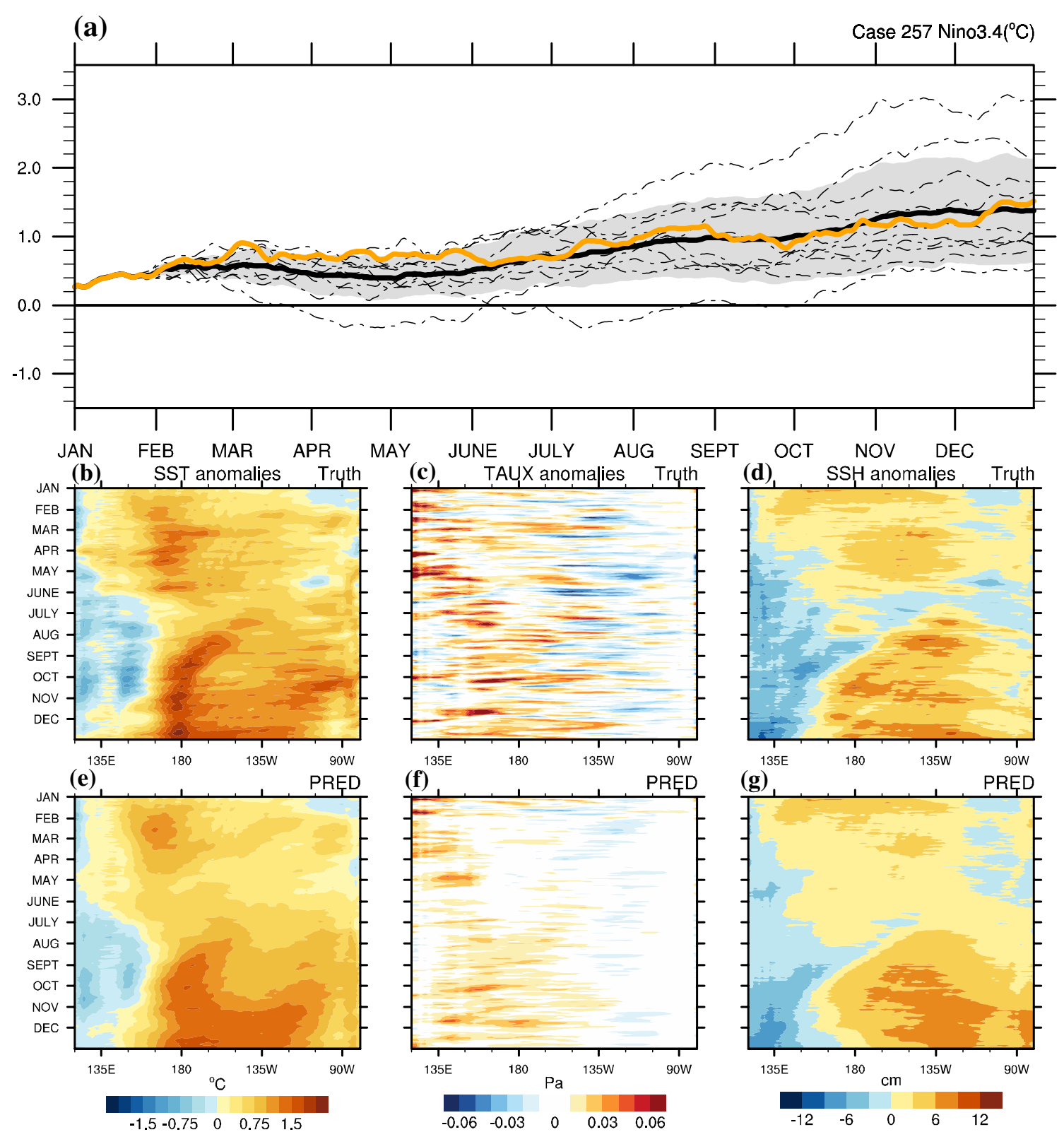

Fig. 6 Same as Fig. 5 except the time series of daily Niño3.4 index of the "truth" is shown as orange line, but for case 257

\section{Predictability of the selected cases}

We first present the fundamental performance of CESM and how well the model could "predict" the three selected cases with different oceanic memory. Figures 5a, 6a and 7a show the daily evolution of Niño3.4 indices from the control simulation (thick color curve), PRED ensemble mean (thick black curve), and the ten ensemble members (thin back curve) for the three cases, respectively. Comparing the control with the ensemble mean, as well as the ensemble spread, one can see that the three warm events can be predicted by the CESM with varying degrees.
Particularly, case 282 with the largest HC recharged exhibits the highest predictability and smallest model spread. In the "truth" of case 282, the recharged HC (Fig. 5d) induces the initial warming in the first few months (Fig. 5b). After June, a series of strong and basin-scale anomalous westerly wind episodes occur with weakened zonal SST gradient, further warming up the central and eastern Pacific and resulting in a strong El Niño event (Fig. 5c). In PRED, the ensemble-mean result still shows strong episodic westerly anomalies in the summer following the initial warming (Fig. 5f), similar to those shown in the original simulation (Fig. 5c). Since these high-frequency anomalies appearing 

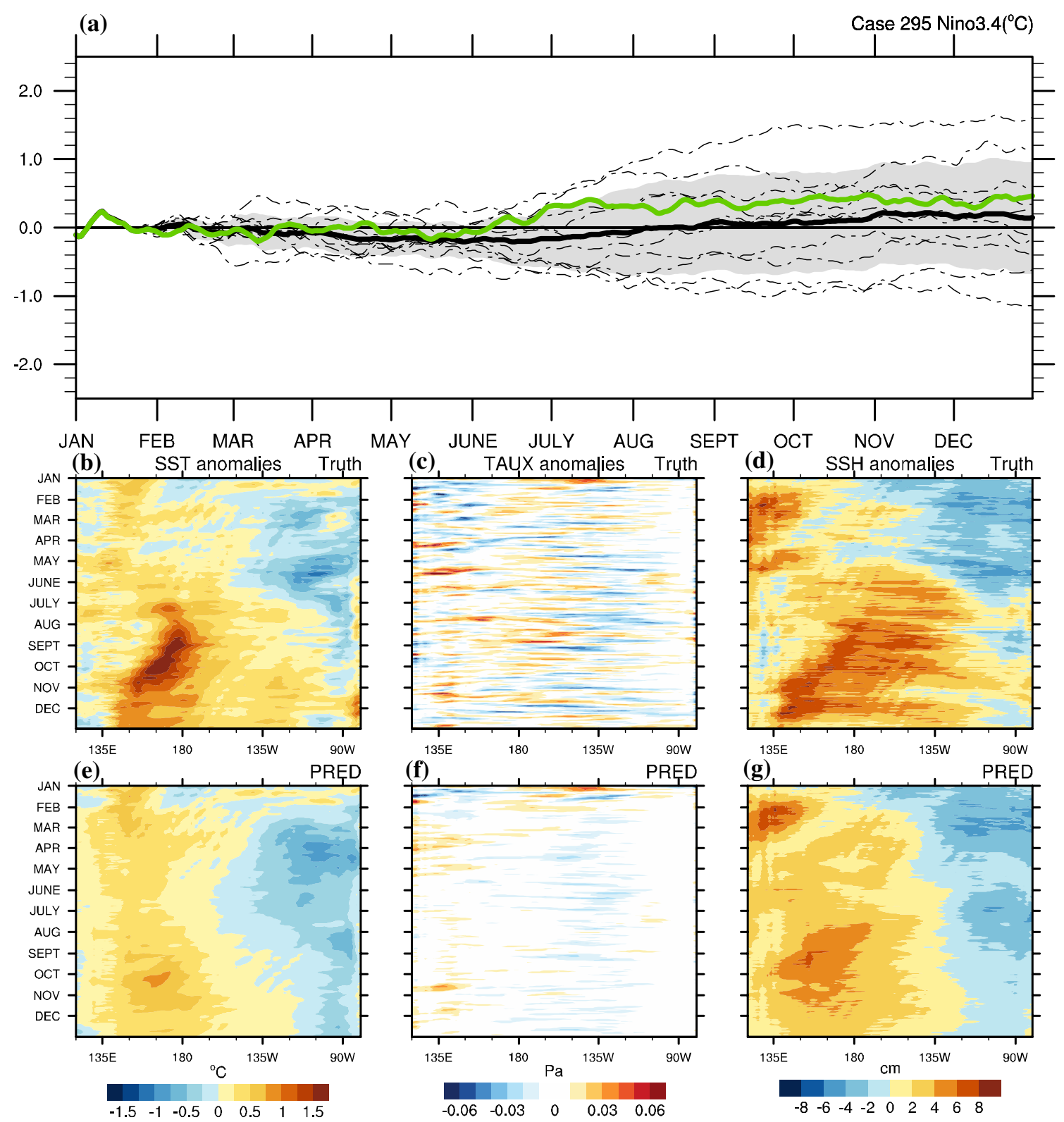

Fig. 7 Same as Fig. 5 except the time series of daily Niño3.4 index of the "truth" is shown as green line, but for case 295

in our ensemble mean prediction seem to be predictable and are accompanied with the warm SST anomalies in the equatorial Pacific (Fig. 5e), we speculate that they may also be part of the ENSO state-dependent wind anomalies. With large $\mathrm{HC}$ and highly predictable westerly anomalies (Fig. 5f, $\mathrm{g}$ ), all of the ten ensemble members of case 282 develop into strong events (Fig. 5a) with little difference in peak amplitude. For case 257, the westerly anomalies in PRED in summer and fall are relatively weaker than case 282 (Fig. 6c, f) because of the relatively weaker initial warming (Fig. 6b, e) but still make considerable contribution to promote comparable warming with the truth (Fig. 6a). By the end of the year, the ensemble-mean result in PRED of case 257 shows a warming with its maximum in the central Pacific (Fig. 6e), resembling a central Pacific El Niño (Kao and $\mathrm{Yu}$ 2009). It should also be noted that although all the ensemble members of case 257 develop into warm events, they display varied amplitudes, i.e. three out of ten cases are out of the range of one standard deviation (two are stronger and one is weaker). With the least recharged HC, case 295 exhibits largest uncertainty (Fig. 7a) as the model-generated noise could significantly influence the evolution of the ocean and the subsequent feedback processes.

The PRED results are consistent with Fedorov et al. (2015) finding: the evolution of the near-neutral state is much more uncertain than the recharged state when analyzing a set of the 
ensemble members, implying that the predictability is proportional to the $\mathrm{HC}$ precondition. Although with different model spreads, the ensemble-mean result of each case does evolve as expected, ruling out the possibility that the cases are totally noise driven.

\section{Seasonally-dependent impact of EWBs}

\subsection{Overall responses of the ocean-atmosphere system to EWBs}

Figures 8,9 and 10 present the overall responses of the ocean to EWBs, including zonal wind stress, sea surface height (SSH), and SST in the equatorial Pacific. As expected, after the EWB forcing is prescribed in the model (Fig. 8), SSH and SST show a series of significant changes in comparison to those in PRED (Figs. 9, 10). Firstly, the
EWBs pull the eastern edge of warm pool westward via inducing westward currents. At the same time, the basinwide EWBs immediately induce westward currents, further triggering upwelling in the equatorial Pacific, especially in the eastern basin where the climatological thermocline shoals. Moreover, the upwelling in the central Pacific generates an eastward propagating upwelling Kelvin wave front. By the processes mentioned above, the equatorial Pacific suffers a significant cooling in the month soon after the occurrence of EWBs. Thenceforth, the SST cooling in central and eastern Pacific prevents the development of the positive Bjerknes feedback (Bjerknes 1969) and the generation of the state-dependent westerly anomalies (Fig. 8), in turn bringing about a subsequent SST cooling (Fig. 10).

It is interesting that the cooling in EWB relative to PRED by the end of the years shows seasonally-dependent amplitude. For EWB3, the Niño3.4 indices for cases 282 and 295 recover
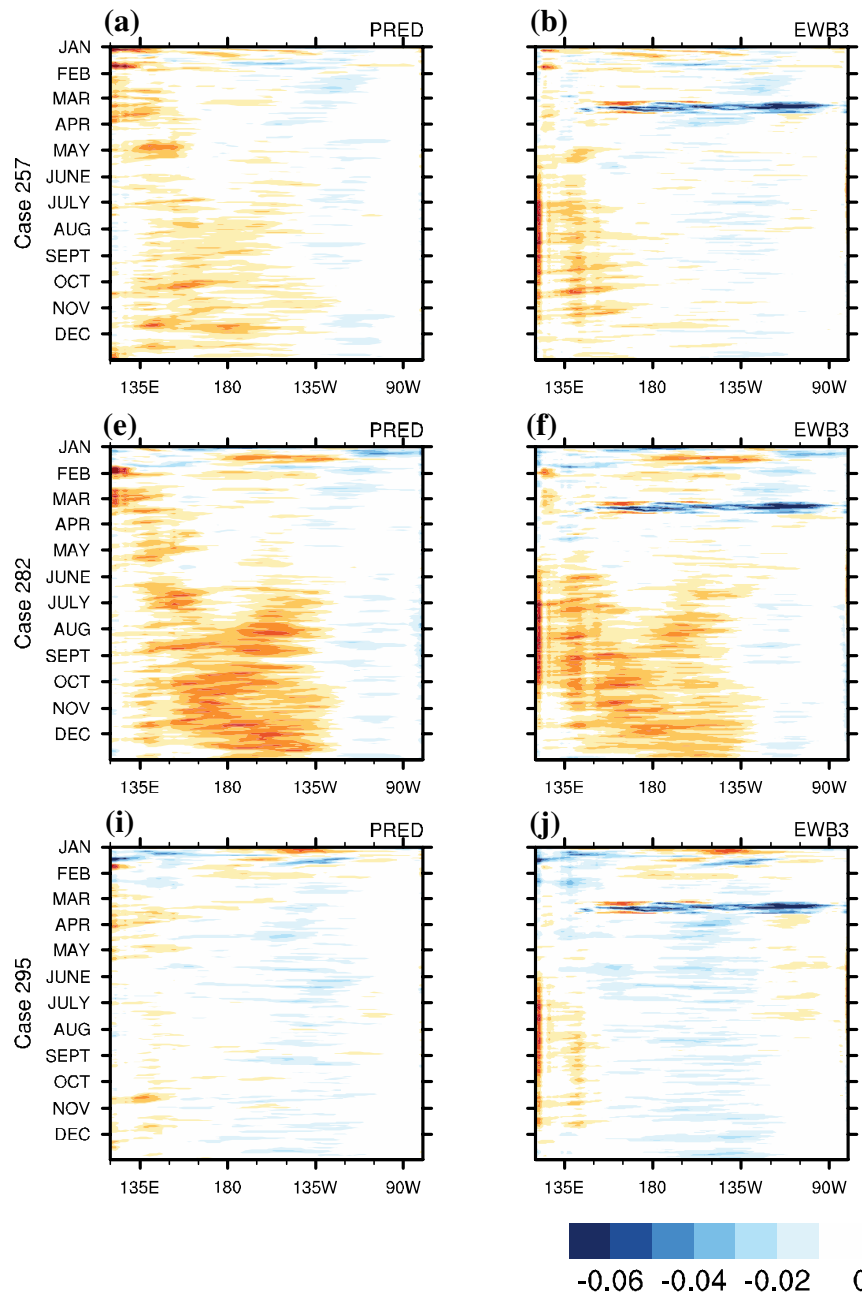

Fig. 8 Time-longitude section of the ten-member ensemble-mean equatorial Pacific $\left(5^{\circ} \mathrm{S}-5^{\circ} \mathrm{N}\right)$ daily zonal wind stress anomalies $(\mathrm{Pa})$ : Column 1 is the PRED without imposed easterly wind bursts, and
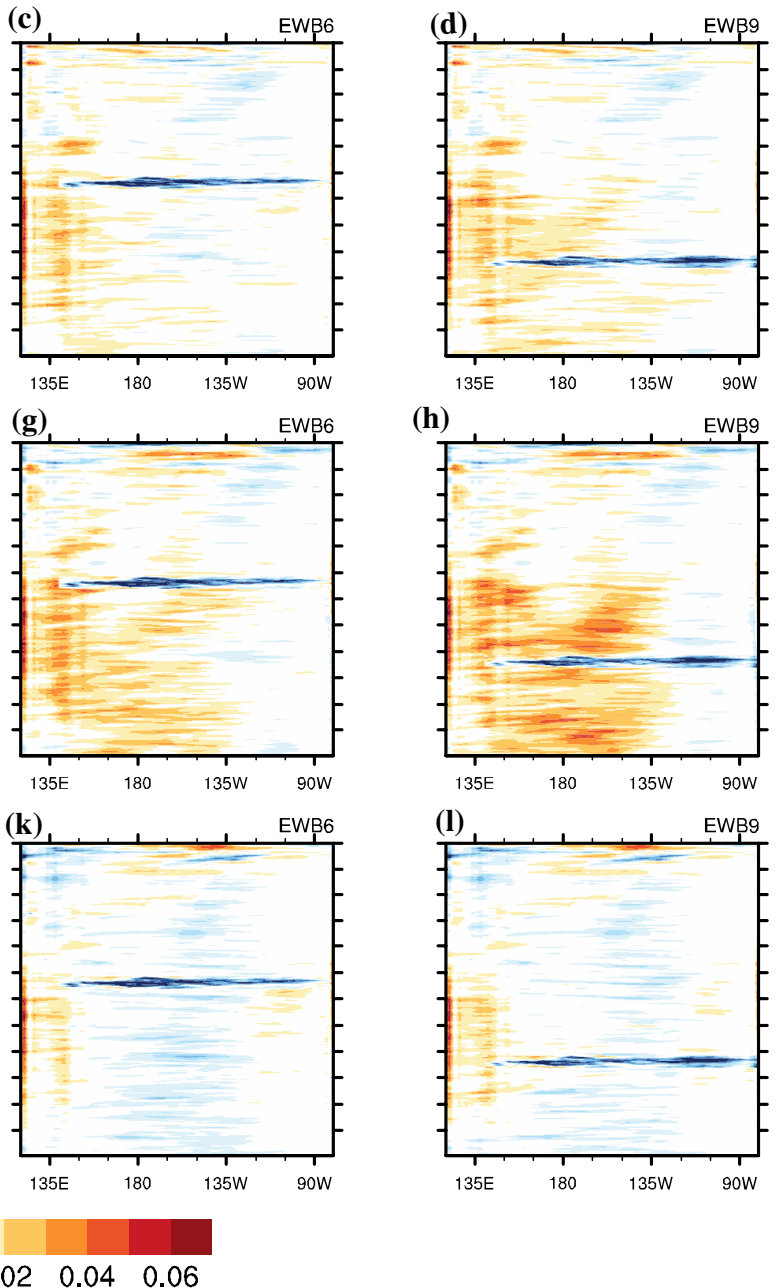

Columns 2-4 are the EWB with imposed easterly wind bursts in March, June, and September, respectively. Row 1-3 are the result of case 257,282 and 295 respectively 

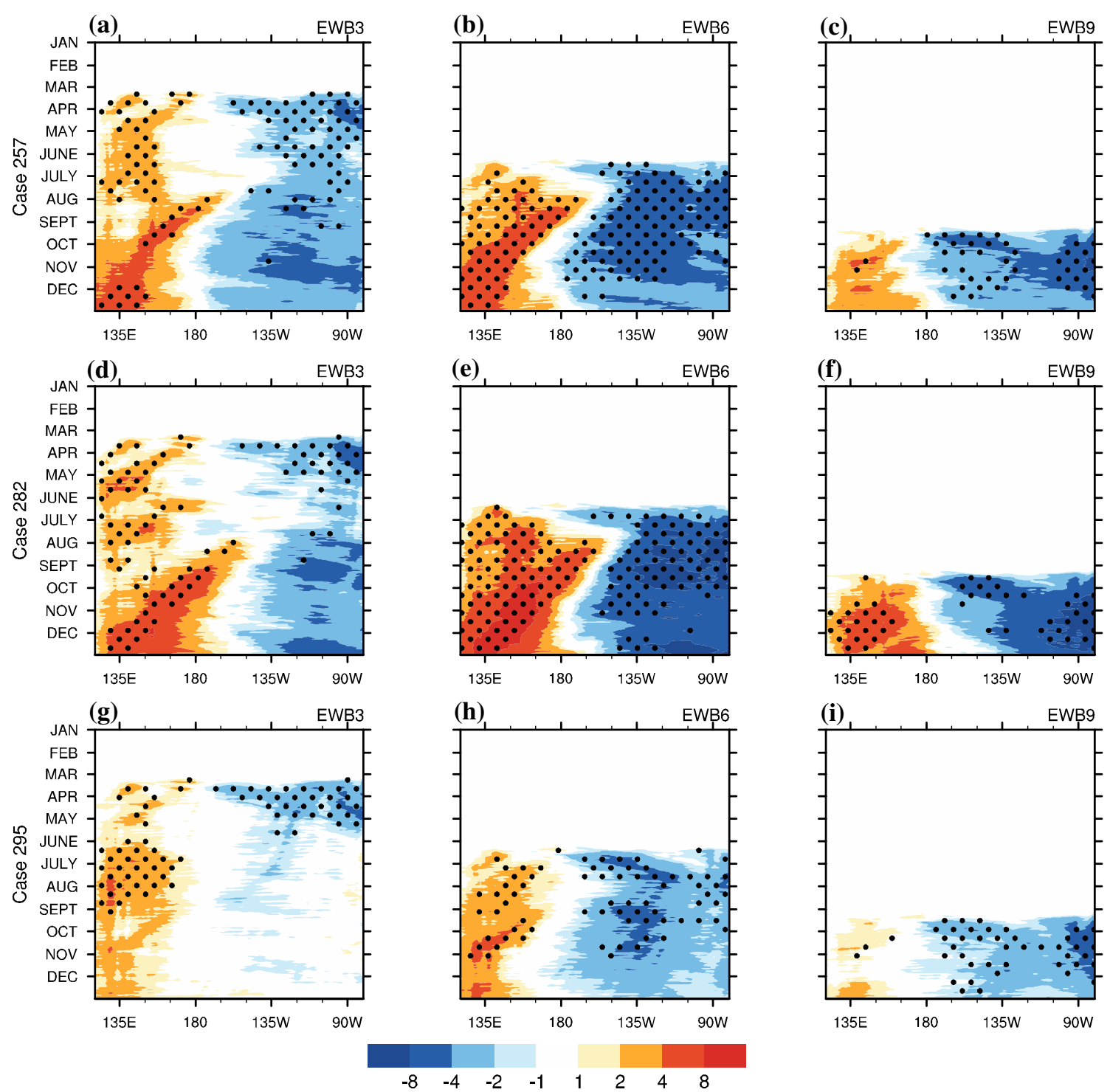

Fig. 9 Time-longitude section of the daily difference in sea surface height $(\mathrm{cm})$ over the equatorial Pacific $\left(5^{\circ} \mathrm{S}-5^{\circ} \mathrm{N}\right)$ between EWB and PRED. Dots show the significant difference at the $95 \%$ confidence level using the Student's $t$-test. In columns $1-3$, easterly wind bursts

from the significant decrease due to the first-step impact of EWBs and rallies to the values comparable to their corresponding PRED runs by the end of the year after (Fig. 11d, g). In contrast, case 257 shows a negative deviation of about $0.7^{\circ} \mathrm{C}$ from PRED in December, decreasing to less than a half of the amplitude in the latter (Fig. 11a). For EWB6 and EWB9, the responses exhibit greater homogeny among the three cases (Fig. 11). Namely, the Niño3.4 index decreases approximately $0.6-0.8{ }^{\circ} \mathrm{C}$ in the EWB6 (Fig. $11 \mathrm{~b}, \mathrm{e}, \mathrm{h}$ ) and $0.4-0.6{ }^{\circ} \mathrm{C}$ in the EWB9 (Fig. 11c, f, i), respectively. In short, the impact is greatest when EWBs are introduced into the model in boreal summer, while the impacts are weaker in spring and fall, with a case dependence in spring (Fig. 11j-1). are introduced into the CESM in March, June, and September, respectively. Rows 1-3 are the results of case 257,282 , and 295 , respectively

\subsection{Thermodynamic factors accounting for seasonally-dependent impacts}

Dynamically, we divide the oceanic response to the prescribed EWBs into two steps, transient and steady responses. Specifically, we consider the first 2 months following the imposed EWBs as the period of transient response and the next 2 months as the period of steady response. The two-step responses can be seen clearly from the composite evolution of the difference between the EWB and control runs for all initialized cases. Figure 12 shows the Hovmoller diagrams of the difference evolution for several key variables along the equator in the first 4 months of initialization (marked as 

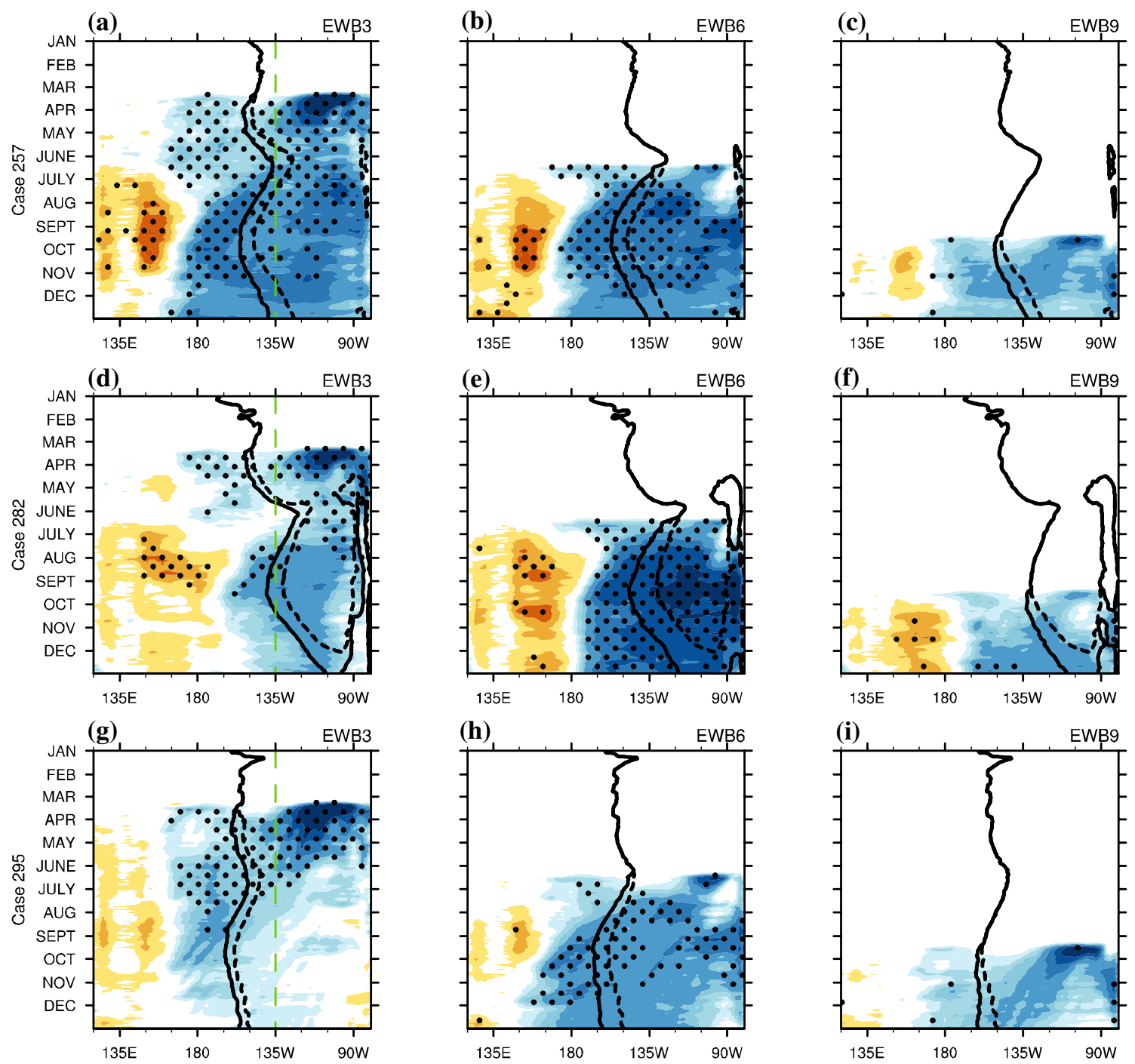

$\begin{array}{llllllllllll}1.2 & -0.9 & -0.7 & -0.5 & -0.4 & -0.3 & -0.2 & 0.1 & 0.3 & 0.5 & 0.7\end{array}$

Fig. 10 Shadings and dots are the same as those in Fig. 9, but for SST $\left({ }^{\circ} \mathrm{C}\right)$. Black contours are the eastern edge of the warm pool (EEWP), defined as the isotherm of $29^{\circ} \mathrm{C}$, dash lines are the EEWP of PRED, and solid lines are the EEWP of EWB. To clearly compare the location of EEWP, the longitude of $135^{\circ} \mathrm{W}$ is shown as green dash lines
M0-M3). The major transient feature is the oceanic wave adjustment to the EWB-induced strong upwelling. In particular, an intensive SST cooling in the eastern equatorial Pacific propagates westward as a Rossby wave front while its strength decreases, reaching the central Pacific by the end of M1 (Fig. 12b). In addition, a strong upwelling signal generated in both D20 and SST near the dateline also propagates eastward as a Kelvin wave packet, which reaches the eastern boundary by the end of M1 without losing its intensity (Fig. 12b, c). Both wave signals are associated with propagating perturbations in the near-surface zonal current (Fig. 12d). On the other hand, a more steady response pattern emerges in the next two months (M2-M3), featuring enhanced easterly winds west of $130^{\circ} \mathrm{E}$ (Fig. 12a), steepened zonal slope of the thermocline (Fig. 12c), cooler SST east of the dateline (Fig. 12b), and stronger basin-wide westward surface current (Fig. 12d). Although the transient response may be dominated by a one-way oceanic adjustment to the EWB forcing, we can demonstrate that the steady response is achieved through a dynamical ocean-atmospheric feedback in the equatorial Pacific that is triggered by the EWB forcing. We also found that the strength of the ocean-atmospheric feedback in the steady response exhibited major seasonal dependency and resulted in the difference in EWBsinducing cooling by the end of the year. 

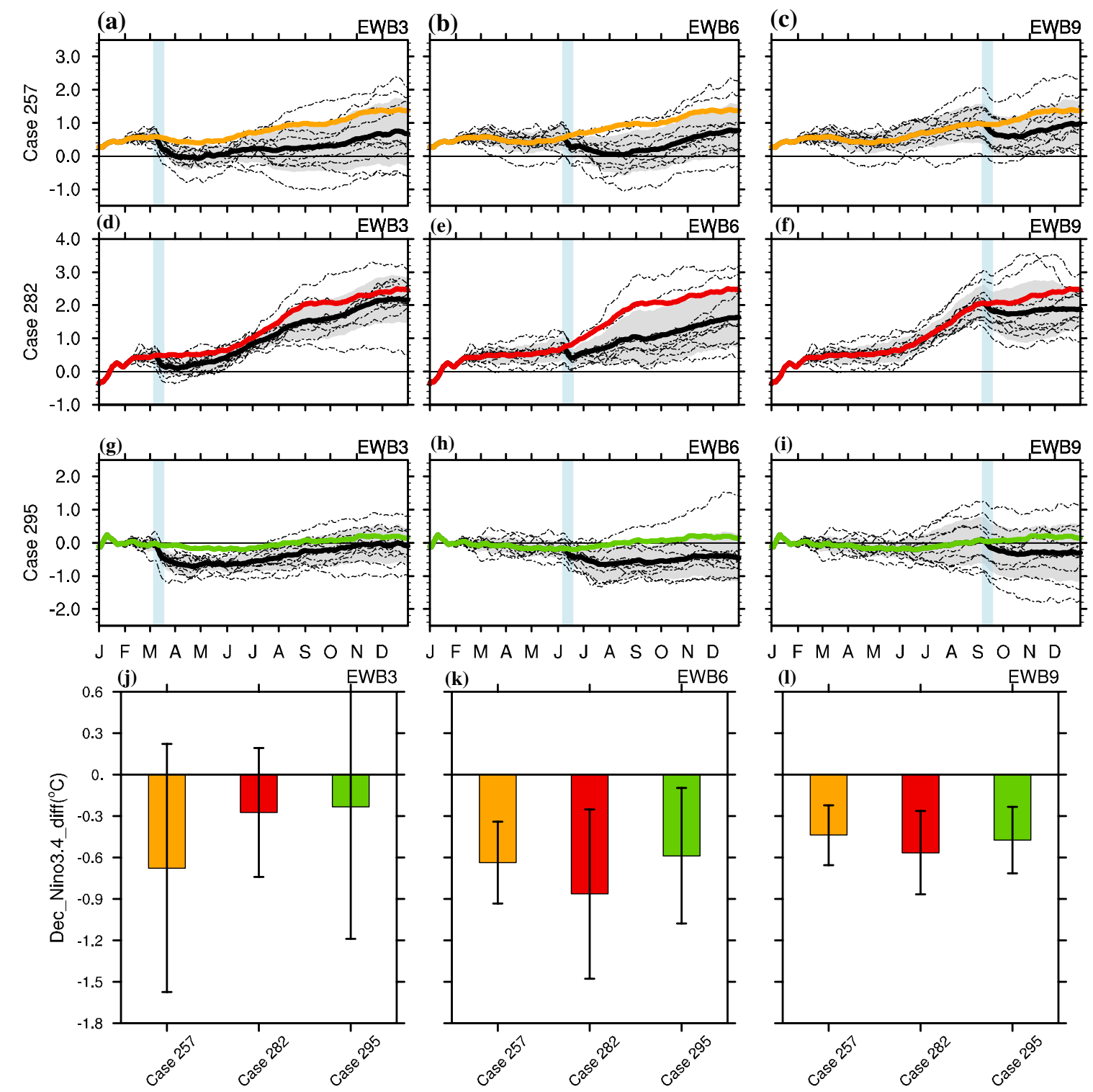

Fig. 11 a-i Time series of daily Niño3.4 index $\left({ }^{\circ} \mathrm{C}\right)$. Color lines show the time series of the PRED, and thin black broken lines show the ten members in the EWB. The ensemble mean is shown by the thick black solid line and the corresponding standard deviation interval by

\subsubsection{Seasonality of background ocean state and ocean- atmosphere interaction}

Figure 13a-c demonstrate the scatterplots of subsequent change in zonal wind stress against the change in SSTA gradient in the period of transient response, showing the difference in atmospheric response to transient SST cooling in the first-step cooling. During the development of El Niño events, the initial warming of the central and eastern Pacific would relax the zonal SST gradient and further weaken the mean trade wind. The weakening of trade wind and the generation of state-dependent westerly anomalies will amplify grey shading. The blue shading bars indicate the periods over which easterly wind bursts are introduced into the CESM. j-l The ensemble difference in December Niño3.4 index $\left({ }^{\circ} \mathrm{C}\right)$ between EWB and PRED. Whiskers indicate the corresponding standard deviation

the warming in turn. In this sense, a subsequent change in the zonal wind stress should be expected to emerge after the cooling of SST by preventing positive Bjerknes feedback. Moreover, previous studies have argued that unstable air-sea interactions are seasonally dependent (Philander et al. 1984; Zebiak and Cane 1987). Therefore, the seasonal dependency of wind response would be expected to result in the seasonally-dependent impact of EWBs on the following development. To further show the efficiency of wind response in generating SST cooling during the subsequent periods, Fig. 13d-f present the scatterplot of zonal wind 

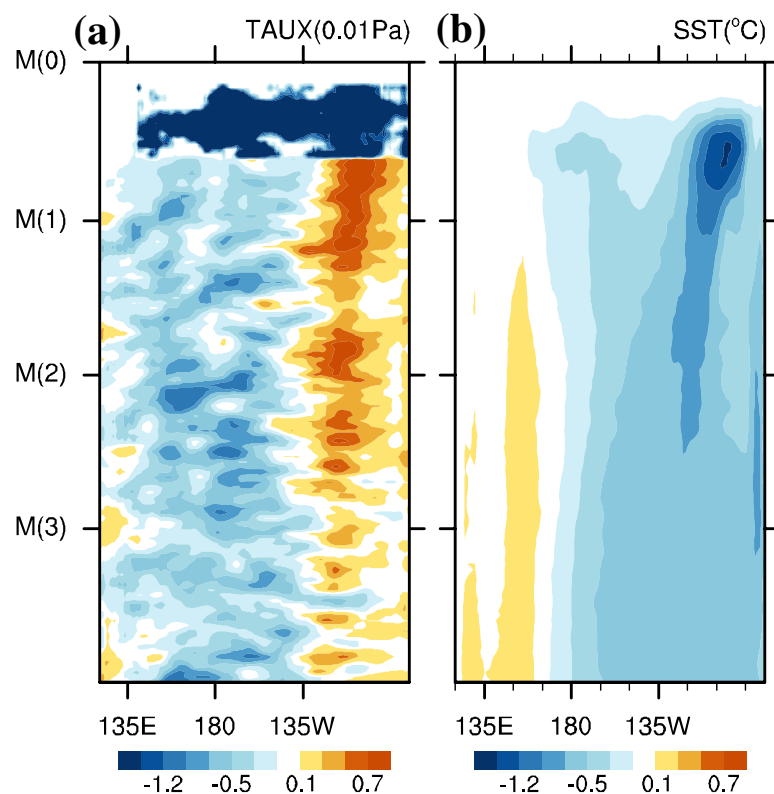

Fig. 12 a Time-longitude section of the ensemble-mean daily difference in zonal wind stress $(0.01 \mathrm{~Pa})$ in the first three months (MarchJune for EWB3, June to September for EWB6, September to Decem-

stress change (same as Figs. a-c) against further SST change over the central and eastern Pacific.

Even though the change in SSTA gradient is smaller in EWB6 than in EWB3, the subsequent change in zonal wind stress is most significant among the three groups (Fig. 13b), reconfirming the strongest Bjerknes feedback in boreal summer argued by the model work conducted with CCSM4 (DiNezio and Deser 2014), the previous version of the CESM used in this study. Moreover, the wind anomalies are most efficient in bringing about further SST change in EWB6 (Fig. 13e). The summertime warmest climatological SST of the annual cycle over the central Pacific favors strong Bjerknes feedback and fast warming growth rate. If an EWB occurs at that time, the expected strong Bjerknes feedback would be disturbed, resulting in a significant weakening of the warming growth. Hence, the cooling amplitude in December of EWB6 is largest among the three EWB experiments. The strongest cooling effect is also related to the unstable ocean state in summer. Utilizing simple and intermediate coupled models, Battisti and Hirst (1989) and Chen et al. (1997) suggested that the tropical Pacific background state was most unstable in boreal summer to promote fast growth of perturbations in the coupled system. It should also be noted that the evolution of EWB6 of case 257 resembles that of 2014 in observation (Figs. 1a, 11b), suggesting that the EWBs in the summer of 2014 possessed the ability to hinder the warming significantly, supported by previous work (e.g. Hu and Fedorov 2016).
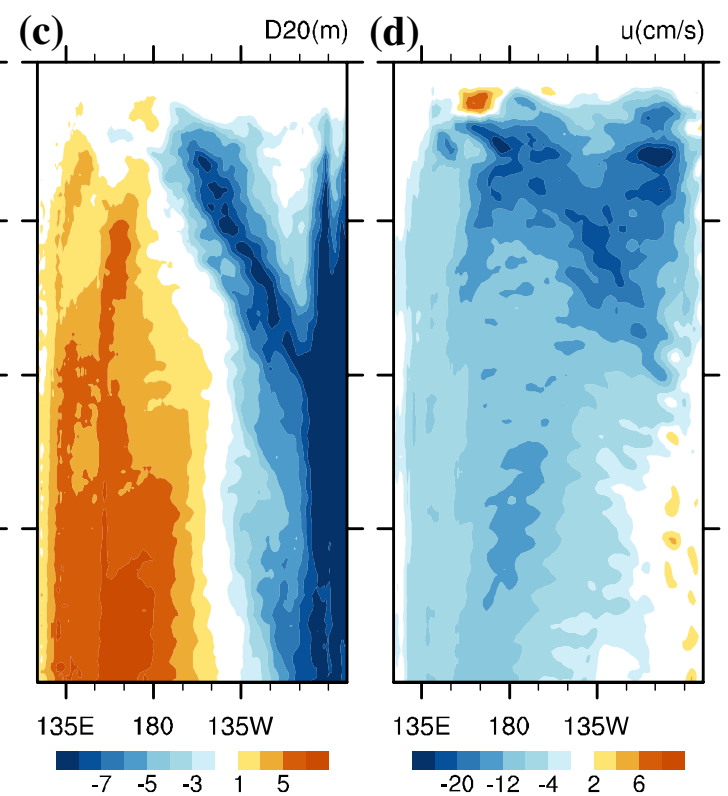

ber for EWB9) over the equatorial Pacific $\left(5^{\circ} \mathrm{S}-5^{\circ} \mathrm{N}\right)$ between EWB and PRED. b-d Same as a, but for SST $\left({ }^{\circ} \mathrm{C}\right)$, D20 (m), and zonal ocean current speed $(\mathrm{cm} / \mathrm{s})$ averaged for $0-50 \mathrm{~m}$

In EWB9, the comparable change in SST is followed by a weaker change in zonal wind stress (Fig. 13c). At the same time, the wind anomalies are less efficient to trigger cooling in the following months (Fig. 13f). It may be due to the reason that with stronger warming over the central and eastern Pacific in autumn, the cooling induced by EWB forcing does not significantly weaken the anomalous zonal SST gradient and prevent the state-dependent westerly anomalies. Moreover, the lack of instability in autumn related to the seasonal placement of the ITCZ (Tziperman et al. 1997) is likely a reason for the weaker response in EWB9. In boreal autumn when the ITCZ shifts to the south of the equator, the background atmospheric convection is relatively weak over the equator, wherefore the Bjerknes feedback is weak in autumn. In this case, the ocean-atmosphere system would be insensible to the high-frequency atmospheric forcing.

For EWB3, nearly no subsequent change in zonal wind stress is observed after the SST cooling under EWB forcing (Fig. 13a), indicating that the atmospheric response to SST anomalies is relatively weak in spring, which was also argued by Zhu et al. (2015). With weak wind anomaly response, the SST change in the subsequent period also presents weaker amplitude in EWB3 (Fig. 13d). Although the wind anomaly response is weak in spring, the EWBs still pull back the east edge of the warm pool (EEWP) to some extent in all of the three cases (Fig. 10a, d, g). Notwithstanding the proximity of the westward shift of EEWP in the three cases, the background location of EEWP shows significant difference among these cases. The EEWP of the PRED in 

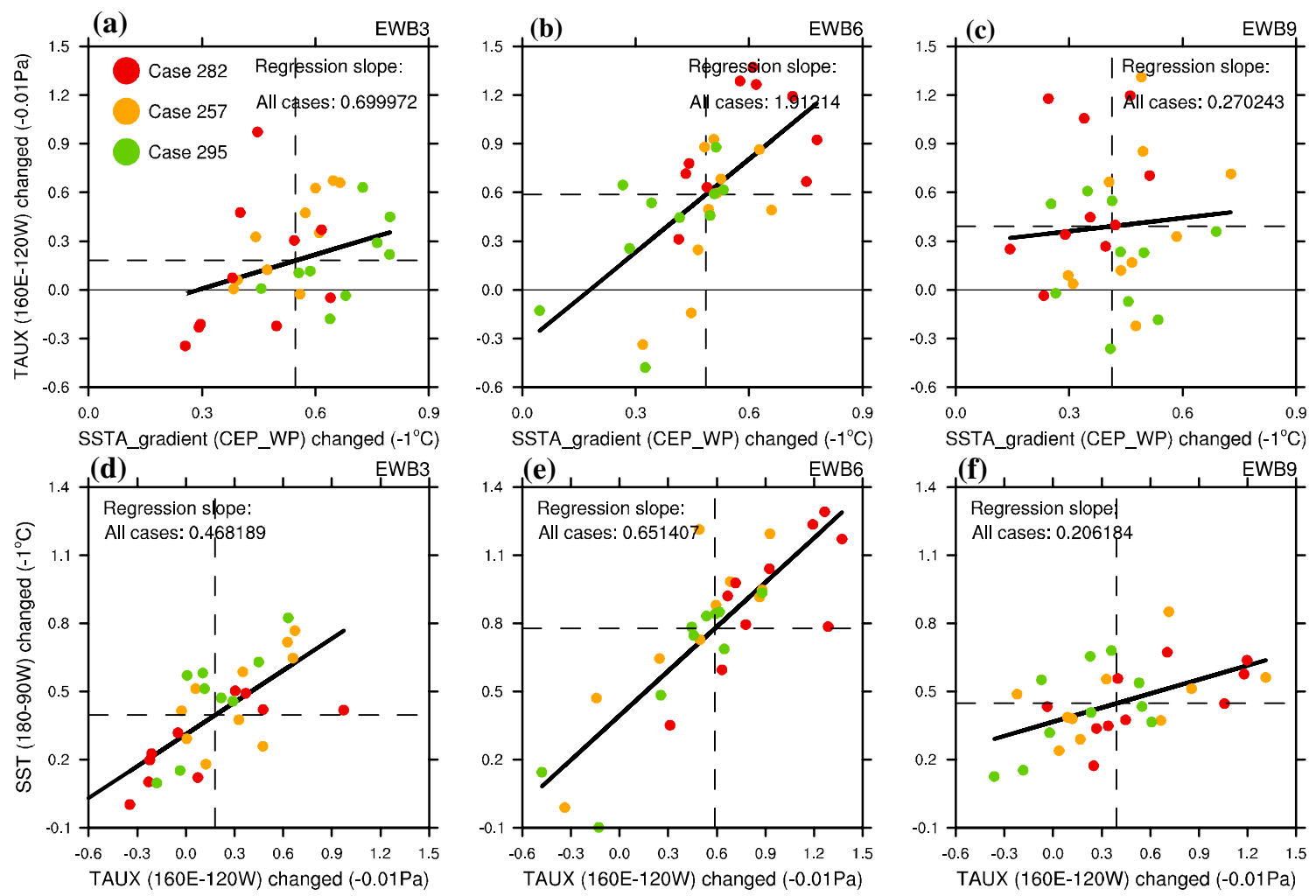

Fig. 13 a-c Scatterplot of zonal SSTA gradient changes (6 March to 30 April, 6 June to 31 July, and 6 September to 31 October for EWB3, EWB6, and EWB9, respectively) against the subsequent (1 April to 31 May, 1 July to 31 August, and 1 October to 30 November) zonal wind stress changes (scaler: $-0.01 \mathrm{~Pa}$ ) over the equator $\left(5^{\circ} \mathrm{S}-5^{\circ} \mathrm{N}\right)$. The zonal SSTA gradient is defined as the difference between the western Pacific (WP; $120^{\circ} \mathrm{E}-160^{\circ} \mathrm{E}, 5^{\circ} \mathrm{S}-5^{\circ} \mathrm{N}$ ) and the

the summer of case 282 is located far eastward than $120^{\circ} \mathrm{W}$ (Fig. 10d), which may lead to an eastward shift of atmospheric convection, favoring the formation of strong positive Bjerknes feedback and a strong El Niño (Lengaigne et al. 2003). Even with a retraction caused by EWBs, the EEWP remains in the eastern Pacific. For case 295, the EEWP of the PRED is located at the central Pacific (Fig. 10g), unfavorable for positive Bjerknes feedback even without the EWBs. Since that, under the EWB forcing, the westward shift of EEWP does not give rise to significant cooling in the following. In short, the changes in EEWP in the EWB3 for cases 282 and 295 could not result in a deviation from the PRED. However, the withdrawal in case 257 exerts considerable influence on the development of the expected warming. Specifically, the EEWP of the PRED is located roughly at $125^{\circ} \mathrm{W}$ (Fig. 10a), which enable, but merely, a relatively strong positive Bjerknes feedback. When the EWB forcing is introduced into the case, the EEWP shifts back to the west of $135^{\circ} \mathrm{W}$ and the coupled system becomes unfavorable for a warming comparable to the PRED. As a result, the EWB3 of case 257 ultimately results in a larger deviation from the central and eastern Pacific (CEP; $\left.180^{\circ}-90^{\circ} \mathrm{W}, 5^{\circ} \mathrm{S}-5^{\circ} \mathrm{N}\right)$. d-f Scatterplot of zonal wind stress changes (same as a-c) against the further (1 May to 30 June, 1 August to 30 September, and 1 November to 31 December) SST changes over the CEP region. Dashed lines indicate the mean values. Dots are ensemble members, black oblique lines are the regression lines of three cases in each seasonal group, and their slopes are shown in each plot

PRED compared with case 282 and case 295. This result is also consistent with that of Fedorov et al. (2015), who emphasized that the location of EEWP was critical for the development of El Niño events. Their results suggest that only the conditions that the EEWP has already reached the eastern Pacific by the mid-year allow for a strong Bjerknes feedback leading to strong warming in the east.

\subsubsection{Relative contributions of ocean dynamic processes}

It is believed that both thermocline feedback $\left(-\bar{w} \frac{\partial T^{\prime}}{\partial z}\right)$ and zonal advective feedback $\left(-u^{\prime} \frac{\partial \bar{T}}{\partial x}\right)$ play important roles in the development of ENSO (Jin and An 1999; An and Jin 2001; Yeh et al. 2009; Hu et al. 2012). In the thermocline feedback, variations of the central and eastern equatorial Pacific thermocline can result in SST anomalies. On the other hand, the zonal advective feedback related to the mean zonal SST gradient can amplify El Niño anomalies during their growth phase with anomalous zonal currents (induced by wind anomalies) (An et al. 1999). Additionally, the 

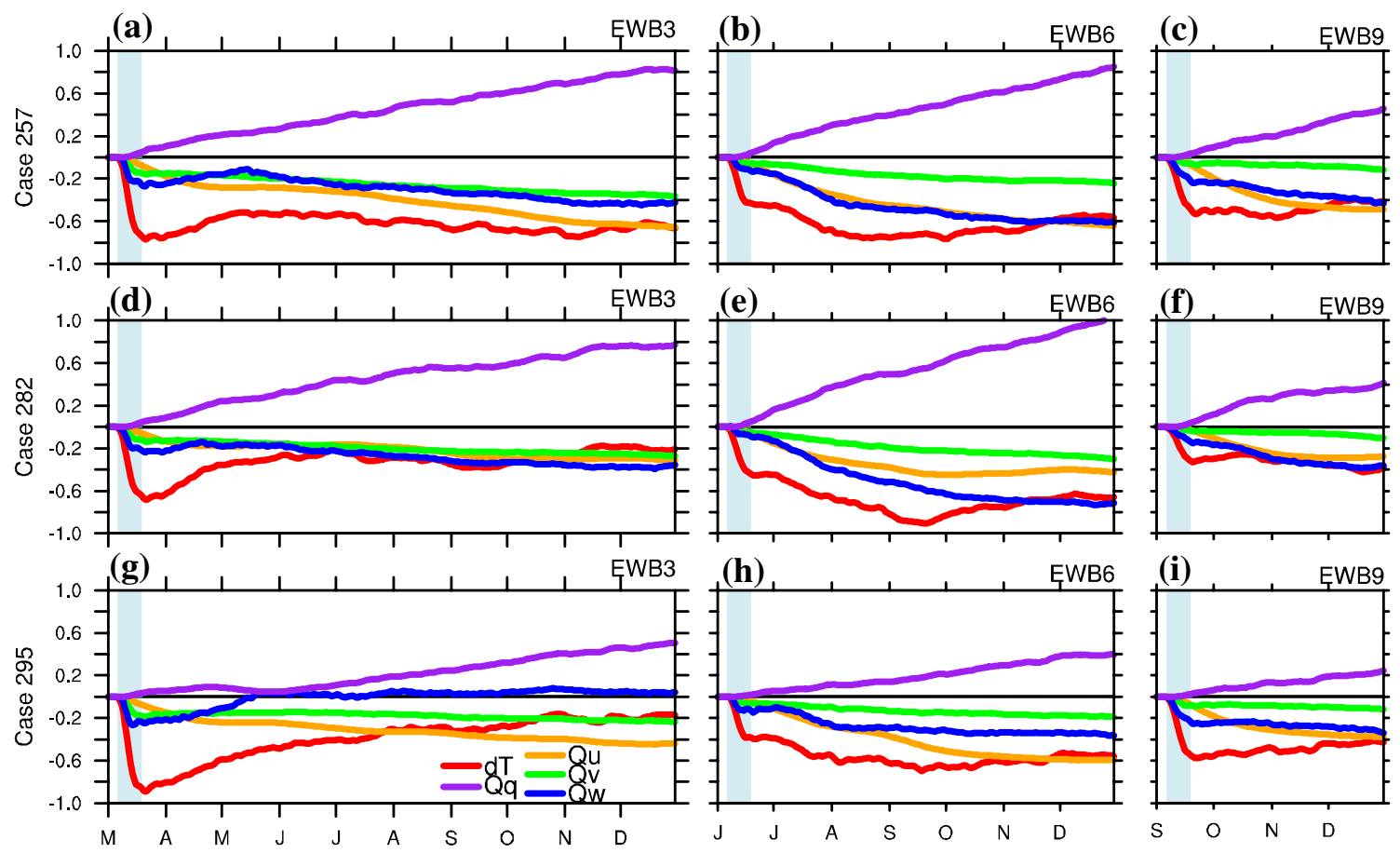

Fig. 14 Time series of time-accumulated mixed layer heat budget terms $\left({ }^{\circ} \mathrm{C}\right)$ averaged in the equatorial central-eastern Pacific $\left(5^{\circ} \mathrm{S}-\right.$ $\left.5^{\circ} \mathrm{N}, 160^{\circ} \mathrm{E}-90^{\circ} \mathrm{W}\right)$. The heat budget terms are computed according to the difference between EWB and PRED. Accumulated mixed layer temperature change (red line) is indicated as "dT/dt", "Qu" represents

Ekman pumping effect should be important for the transient oceanic response to the wind anomalies that we have discussed in the previous section.

To illustrate the relative contributions of these ENSO feedback processes, we compute a mixed layer heat budget analysis according to the difference between EWB and PRED. Figure 14 shows the evolution of composite timeaccumulated heat budget response induced by the EWB forcing averaged in the central and eastern Pacific. As expected, the amplitude of the first-step response is dominated by the vertical advection terms (blue lines), which are related to the Ekman pumping effect $\left(-w^{\prime} \frac{\partial \bar{T}}{\partial z}\right)$ and the thermocline feedback. During the subsequent change, the zonal advection terms (yellow lines) grow gradually into a comparable or even larger amplitude, reflecting the increasing importance of zonal advective feedback induced by the EWBs. With a smaller amplitude, meridional advection change (green lines) makes limited contribution to the SST change. Meanwhile, the heat flux term (purple lines) driven by the atmospheric forcing damps the SST cooling. In addition, Fig. 14 shows that differences in the heat budget terms exist among three groups of EWB runs, reconfirming the seasonallydependent impact of EWBs.

the zonal advection term (orange line), "Qv" stands for the meridional advection term (green line), "Qw" the vertical advection term (blue line), and "Qq" the net surface heat flux term. The blue shading bars indicate the periods over which easterly wind bursts were introduced into the CESM

To further investigate the different roles of the feedback processes in vertical and zonal direction, we show the hovmoller diagrams for the time-accumulated vertical (Fig. 15) and zonal advection (Fig. 16) terms in the equatorial Pacific. Figure $15 \mathrm{a}-\mathrm{c}$ show that the cooling related to the vertical advection is restricted to the coastal region but with a large intensity, implying that the EWBs may shift the SST warming center to the west of the original location and modulate the category of the events. To be more specific, the Ekman pumping associated with the anomalous upwelling caused by EWB dominates the vertical term, but shows little seasonality for its uniform amplitude among the three seasons (Fig. 15d-f). On the other hand, the thermocline feedback, which is related to the change in vertical temperature gradient, does to some extent contribute to the seasonally-dependent impacts of EWB with warming effect in EWB3 but cooling effect in EWB6 and EWB9 (Fig. 15g-i). The influence with reverse sign might be largely related to the original vertical velocity in different seasons since EWB should raise the thermocline and enhance the vertical temperature gradient in all seasons.

However, it should still be noted that the influence of the thermocline feedback should not take the dominant responsibility for the seasonal dependency because of its restricted zonal scale. Instead, although the zonal advection 


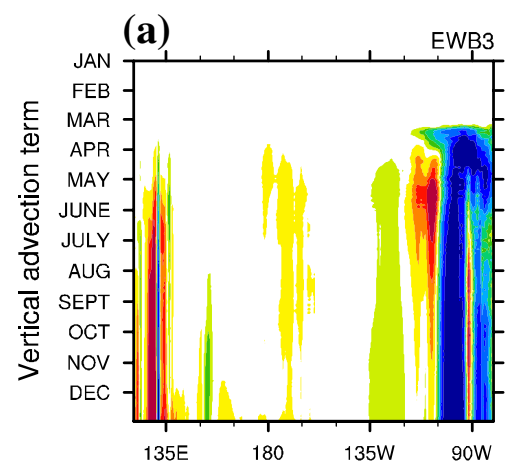

(d)

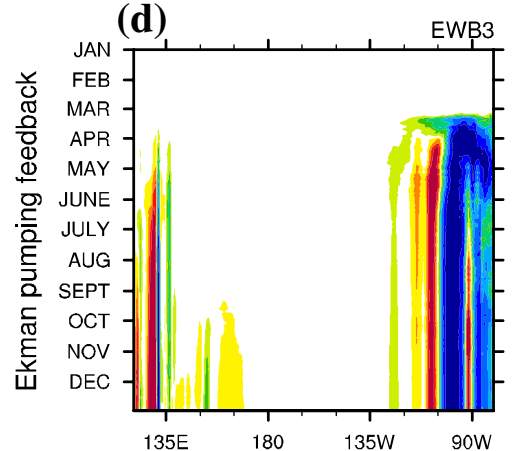

(g)

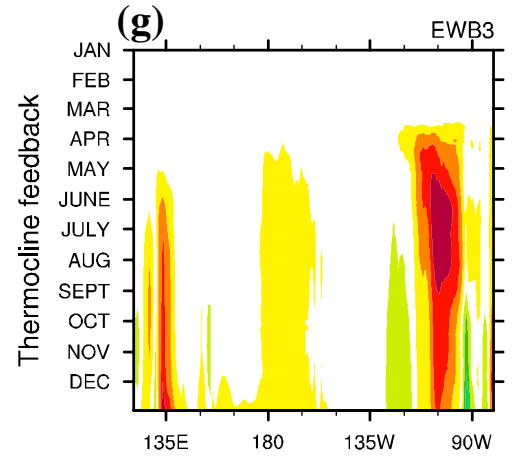

(b),

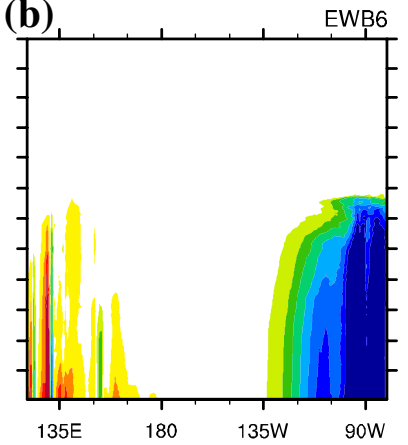

(e)

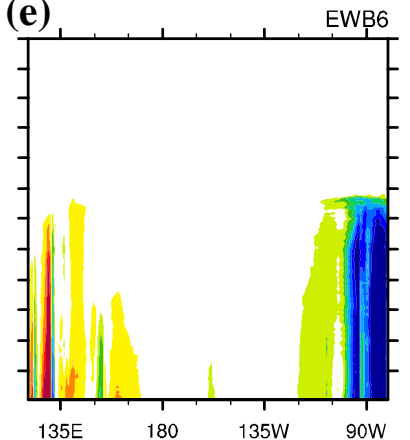

(h),

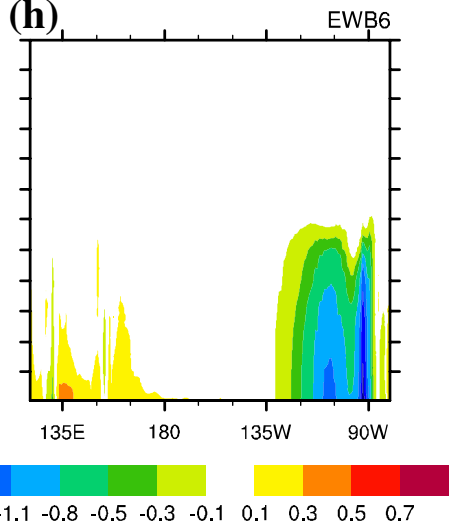

$\begin{array}{lllllllllll}-2 & -1.5 & -1.1 & -0.8 & -0.5 & -0.3 & -0.1 & 0.1 & 0.3 & 0.5 & 0.7\end{array}$ (c)

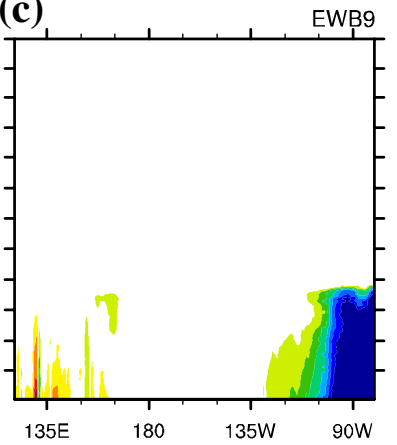

(f)

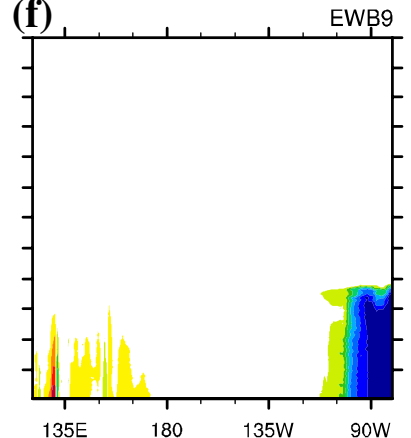

(i)

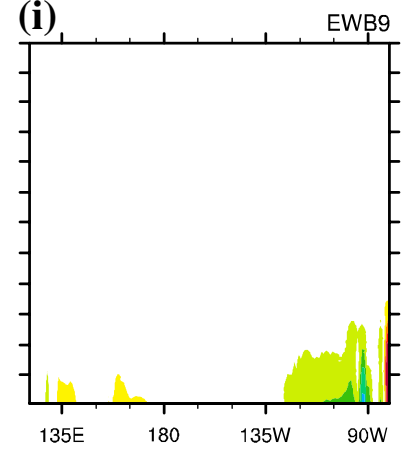

Fig. 15 Time-longitude section of the time-accumulated heat-budget terms in vertical direction $\left({ }^{\circ} \mathrm{C}\right)$ averaged among three cases. a-c Are the sum of the vertical advection terms (including nonlinear term), $\mathbf{d}-$ f are the Ekman pumping feedback term $\left(-w^{\prime} \frac{\partial \bar{T}}{\partial z}\right)$, and $\mathbf{g}-\mathbf{i}$ are the thermocline feedback term $\left(-\bar{w} \frac{\partial T^{\prime}}{\partial z}\right)$

separately). This result suggests that the seasonally-dependent impacts of EWBs are to a great extent tied to the zonal advective feedback process associated with the subsequent ocean-atmosphere interaction after the first-step cooling.

In summary, the EWB-induced Ekman pumping generates immediate equatorial upwelling and surface cooling in the first-step response. However, since this process is fast and transient, it does not contribute significantly to the seasonality of the response to EWBs. Secondly, both thermocline feedback and zonal advective feedback are longer lasting and can make more substantial contributions in the second-stage response. Thirdly, between these two, the zonal advective feedback is the primary factor responsible for the seasonal dependence of the EWB impact. 

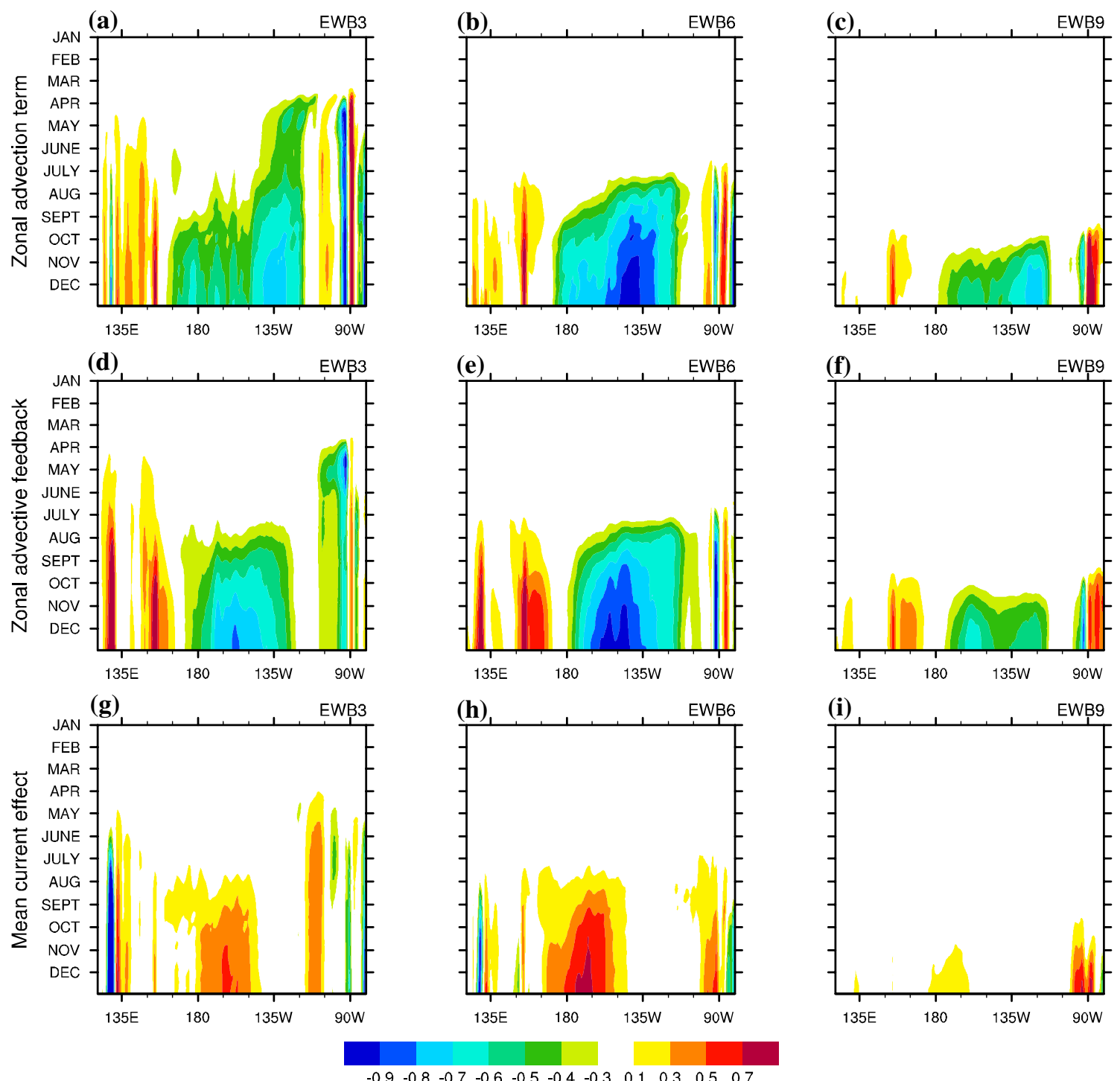

Fig. 16 Same as Fig. 15 but for the zonal direction. a-c Are the sum of the zonal advection terms (including nonlinear term), $\mathbf{d}-\mathbf{f}$ are the zonal advective feedback term $\left(-u^{\prime} \frac{\partial \bar{T}}{\partial x}\right)$, and $\mathbf{g}-\mathbf{i}$ are the mean current effect term $\left(-\bar{u} \frac{\partial T^{\prime}}{\partial x}\right)$

\section{Summary and discussion}

In this study, we have investigated the importance of easterly wind bursts for the development and evolution of El Niño events. Previous studies (Min et al. 2015; Hu and Fedorov 2016; Zhu et al. 2016) claimed that an unpredicted easterly wind event was responsible for the weaker-than-predicted amplitude of the equatorial Pacific warming in the winter of 2014. Meanwhile, other studies emphasized the lack of westerly wind events as the primary cause of the subsequent development (Menkes et al. 2014; Chiodi and Harrison 2017; Puy et al. 2017). Indeed, WWBs are important for the onset and development of El Niño events by generating warm zonal advection and triggering downwelling Kelvin wave. However, it should also be noted that WWBs could be state dependent: a weaker SST gradient in the central Pacific favors more WWBs via the Bjerknes feedback. Since the EWBs could cool down SST as the counterpart of WWBs, the changed ocean state could further influence the subsequent development of the ocean-atmosphere system, including the occurrence and amplitude of WWBs. Seeing the great amplitude and large zonal scale of the EWB in 2014, it should be convictive that the EWB did contribute to the weaker-than-expected warming which may also be partly contributed by the lack of WWBs. In this case, we try to figure what would happen if comparable EWB occurs during other El Niño events with the consideration of the timing of occurrence and the background ocean state (i.e. HC).

Motivated by observed features, we conducted a series of sensitivity experiments using the fully coupled CESM 
Fig. 17 a Time series of pentad area-averaged zonal wind stress (black line, unit: Pa, tick mark on the right) and mixed layer heat budget terms (color lines, unit: ${ }^{\circ} \mathrm{C} /$ month, tick mark on the left) in the equatorial central Pacific region $\left(5^{\circ} \mathrm{S}-5^{\circ} \mathrm{N}\right.$, $\left.160^{\circ} \mathrm{E}-160^{\circ} \mathrm{W}\right)$. "dT/dt" indicates mixed layer temperature tendency (red line), "Qu" represents the zonal advection term (orange line), "Qv" stands for the meridional advection term (green line), "Qw" the sum of vertical advection and diffusion terms (blue line), and "Qq" the net surface heat flux term. b Same as a, but the mixed layer heat budget terms are averaged in the equatorial eastern Pacific region $\left(5^{\circ} \mathrm{S}-5^{\circ} \mathrm{N}\right.$, $130^{\circ} \mathrm{W}-90^{\circ} \mathrm{W}$ )
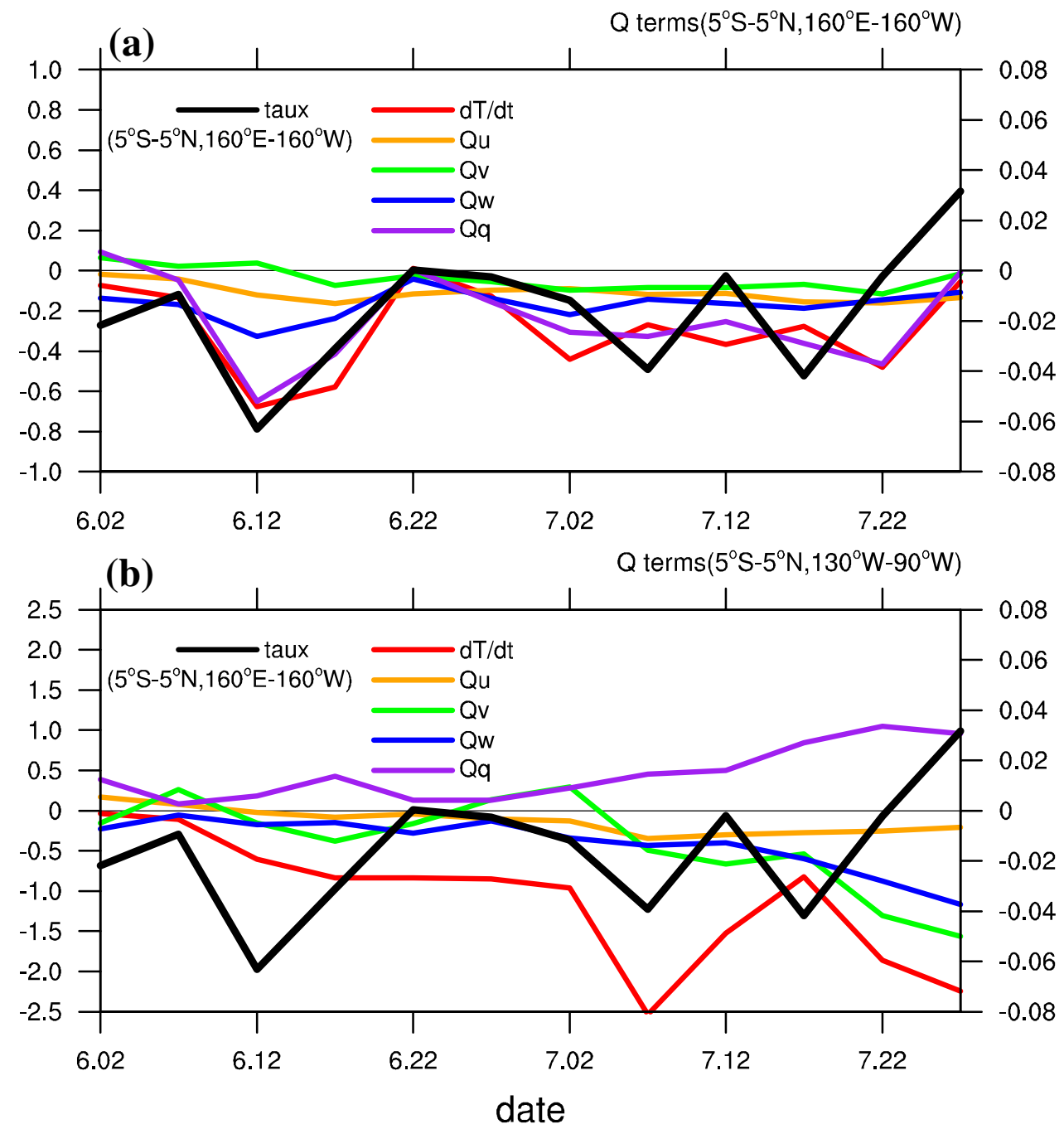

with prescribed EWBs to investigate the their impacts. Model simulations show that the impacts of EWBs on the development of El Niño events display a seasonal dependence. The EWB-induced SST change by the end of the year is largest if EWBs occur in June, when the ocean state is most unstable (Battisti and Hirst 1989; Chen et al. 1997) and the ocean-atmosphere interaction is strongest (DiNezio and Deser 2014). We also notice that the influence of the EWBs in June on case 275 bears close resemblance to the observed feature in 2014, suggesting that the observed EWB in 2014 should play a dominant role in hindering the warming. With stronger anomalous zonal SST gradient and more stable background state, the boreal autumn EWB-induced cooling is smaller than that of the summertime. For group EWB3, a case-dependent result related to the migration of EEWP in different cases is found, indicating the importance of warm pool extension. A mixed layer heat budget analysis also confirms the seasonally-dependent impact of EWBs and further suggests that the seasonally-dependent impact of EWBs is tied to the zonal advective feedback process associated with the subsequent ocean-atmosphere interaction. In addition, the seasonal dependency is to some extent contributed by the thermocline feedback which is related to the background vertical velocity in different seasons. Meanwhile, the transient Ekman pumping that dominates the vertical advection shows little seasonality but tends to shift the warming center westward and modulate the category of the events. To sum up, the seasonally-dependent impacts of EWBs on the development of El Niño events are closely related to the seasonality of background ocean state and ocean-atmosphere interaction.

It is noteworthy however that we have neglected the impact of EWBs on the heat exchange between the atmosphere and the ocean in our model framework. Figure 17 displays the mixed layer heat budget in response to the EWBs in summer 2014 derived from the GODAS. As illustrated, the cooling of SST response to the EWBs is induced not only by dynamical processes but also by the release of heat content from the ocean caused by strong-than-normal evaporation. Nevertheless, the heat flux terms generally act as a 
damping factor, while the dynamical processes would play more dominant roles for the response to the EWBs. In this case, our primary focus on the dynamical processes in this study is reasonable and plausible.

When examining the corresponding spread of ensemble members, we notice that, no matter with prescribed EWBs or not, the predictability of the case with greater heat content recharged is better, while the evolution of the neutral case is much more uncertain. In fact, model-generated noises emerge more easily from the neutral case and heat recharge state could help trigger state-dependent westerly anomalies. As a result, with a uniform slight perturbation in the initial condition, the neutral case would develop into more variable ending states.

Our results reconfirm the unstable ocean-atmosphere coupled system before summer, to which high-frequency atmospheric processes could make significant impacts. Considering the lack of predictability of high-frequency atmospheric activity, it may be difficult to predict the final state of ENSO events long before summer. Hence, to obtain a breakthrough on ENSO prediction after the choke point that we have confronted since the 2000s (Barnston and Tippet 2012), greater efforts in improving the predictability of high-frequency atmospheric activity should be made in future research.

Acknowledgements We are grateful to Dr. Zeng-Zhen $\mathrm{Hu}$ of the NOAA Climate Prediction Center for providing part of the GODAS analysis data. This study was supported by the National Key Research and Development Program of China (2016YFA0602703), the National Natural Science Foundation of China (Grants 41690123, 41690120, and 91637208), the "111-Plan" Project of China (Grant B17049), and the Jiangsu Collaborative Innovation Center for Climate Change. B. Huang is supported by grants from NSF (AGS-1338427), NASA (NNX14AM19G), and NOAA (NA14OAR4310160 and NA17OAR4310144). Computing resource for the CESM experiments was provided by the high-performance grid computing platform of Sun Yat-sen University and the "Tianhe-2" in the National Supercomputer Centre in Guangzhou.

Open Access This article is distributed under the terms of the Creative Commons Attribution 4.0 International License (http://creativeco mmons.org/licenses/by/4.0/), which permits unrestricted use, distribution, and reproduction in any medium, provided you give appropriate credit to the original author(s) and the source, provide a link to the Creative Commons license, and indicate if changes were made.

\section{References}

Alexander MA, Bladé I, Newman M, Lanzante JR, Lau NC, Scott JD (2002) The atmospheric bridge: the influence of ENSO teleconnections on air-sea interaction over the global oceans. J Clim 15(16):2205-2231

An S, Jin FF (2001) Collective role of thermocline and zonal advective feedbacks in the ENSO mode. J Clim 14(16):3421-3432
An S, Jin FF, Kang I (1999) The role of zonal advection feedback in phase transition and growth of ENSO in the Cane-Zebiak model. J Meteorol Soc Jpn 77(77):1151-1160

Barnston A, Tippett M (2012) Skill of real-time seasonal ENSO model predictions during 2002-11: is our capability increasing? Bull Am Meteorol Soc 93(5):ES48-ES50

Battisti DS, Hirst AC (1989) Interannual variability in a tropical atmosphere-ocean model: influence of the basic state, ocean geometry and nonlinearity. J Atmos Sci 46:1687-1712

Behringer DW, Xue Y (2004) Evaluation of the global ocean data assimilation system at NCEP: The Pacific Ocean. Eighth Symposium on Integrated Observing and Assimilation Systems for Atmosphere, Oceans, and Land Surface, AMS 84th Annual Meeting, Washington State Convention and Trade Center, Seattle, Washington, 11-15

Bjerknes J (1969) Atmospheric teleconnections from the equatorial Pacific. Mon Weather Rev 97(3):163-172

Boulanger J-P, Menkes C, Lengaigne M (2004) Role of highand low frequency winds and wave reflection in the onset, growth and termination of the 1997-1998 El Niño. Clim Dyn 22(2-3):267-280

Busalacchi AJ, Cane MA (1988) The effect of varying stratification on low-frequency equatorial motions. J Phys Oceanogr 18(6):801-812

Cane MA, Zebiak SE, Dolan SC (1986) Experimental forecasts of El Niño. Nature 321(6073):827

Capotondi A (2013) ENSO diversity in the NCAR CCSM4 climate model. J Geophys Res Oceans 118:4755-4770. https://doi. org/10.1002/jgrc.20335

Chen Y, Battisti DS, Palmer TN, Barsugli J, Sarachik ES (1997) A study of the predictability of tropical Pacific SST in a coupled atmosphere-ocean model using singular vector analysis: The role of the annual cycle and the ENSO cycle. Mon Weather Rev 125:831-845. https://doi.org/10.1175/15200493(1997)125\%3C0831:ASOTPO\%3E2.0.CO;2

Chen D, Lian T, Fu C, Cane MA, Tang Y, Murtugudde R (2015) Strong influence of westerly wind bursts on El Niño diversity. Nat Publ Group 8(5):339-345

Chiodi AM, Harrison DE (2014) Equatorial Pacific easterly wind surges and the onset of La Niña events. J Clim 28(2):776-792

Chiodi AM, Harrison DE (2017) Observed El Niño SSTA development and the effects of easterly and westerly wind events in 2014-2015. J Clim 30(4):1505-1519

Clarke AJ (2014) El Niño physics and El Niño predictability. Annu Rev Mar Sci 2014(6):79-99, https://doi.org/10.1146/annurevmarine-010213-135026

Deser C et al (2012) ENSO and Pacific decadal variability in the Community Climate System Model version 4. J Clim 25(8):2622-2651

Dewitte B, Purca S, Illig S, Renault L, Giese BS (2008) Low frequency modulation of intraseasonal equatorial kelvin wave activity in the Pacific from soda: 1958-2001. J Clim 21(22):6060-6069

DiNezio PN, Deser C (2014) Nonlinear controls on the persistence of La Niña. J Clim 27:7335-7355

Dommenget D, Bayr T, Frauen C (2013) Analysis of the non-linearity in the pattern and time evolution of El Niño southern oscillation. Clim Dyn 40:2825-2847. https://doi.org/10.1007/s0038 2-012-1475-0

Fedorov AV (2002) The response of the coupled tropical ocean atmosphere to westerly wind bursts. Q J R Meteor Soc 128(579):1-23

Fedorov AV, Philander SG (2001) A stability analysis of tropical oceanatmosphere interactions: bridging measurements and theory for El Nino. J Clim 14(14):3086-3101. https://doi.org/10.1175/15200442(2001)014\%3C3086:Asaoto\%3E2.0.Co;2

Fedorov AV, Hu S, Lengaigne M, Guilyardi E (2015) The impact of westerly wind bursts and ocean initial state on the development, and diversity of El Niño events. Clim Dyn 44(5-6):1381-1401 
Gebbie G, Eisenman I, Wittenberg AT, Tziperman E (2007) Modulation of westerly wind bursts by sea surface temperature: a semistochastic feedback for ENSO. J Atmos Sci 64(9):3281-3295. https://doi.org/10.1175/JAS4029.1

Harrison DE, Schopf PS (1984) Kelvin-wave-induced anomalous advection and the onset of surface warming in El Niño events. Mon Weather Rev 112(5):923-933

Hu S, Fedorov AV (2016) Exceptionally strong easterly wind burst stalling El Niño of 2014. Proc Natl Acad Sci 113(8):201514,182. https://doi.org/10.1073/pnas.1514182113

Hu S, Fedorov AV (2017) The extreme El Niño of 2015-2016: the role of westerly and easterly wind bursts, and preconditioning by the failed 2014 event. Clim Dyn 1-19

Hu ZZ, Kumar A, Jha B, Wang W, Huang B, Huang B (2012) An analysis of warm pool and cold tongue El Niños: air-sea coupling processes, global influences, and recent trends. Clim Dyn 38(9-10):2017-2035

Huang B, Xue Y, Zhang D, Kumar A, Mcphaden MJ (2010) The NCEP GODAS ocean analysis of the tropical Pacific mixed layer heat budget on seasonal to interannual time scales. J Clim 23(18):4901-4925

Ineson S, Balmaseda MA, Davey MK, Decremer D, Dunstone NJ, Gordon M, Ren HL, Scaife AA, Weisheimer A (2018) Predicting El Niño in 2014 and 2015. Sci Rep 8:10733. https://doi.org/10.1038/ s41598-018-29130-1

Jin FF (1997) An equatorial ocean recharge paradigm for ENSO. Part I: conceptual model. J Atmos Sci 54(7):811-829

Jin FF, An S (1999) Thermocline and zonal advective feedbacks within the equatorial ocean recharge oscillator model for ENSO. Geophys Res Lett 26(19):2989-2992

Kao H, Yu J (2009) Contrasting eastern-pacific and central-pacific types of ENSO. J Clim 22(3):615-632

Larson S, Kirtman B (2013) The Pacific meridional mode as a trigger for ENSO in a high-resolution coupled model. Geophys Res Lett 40(12):3189-3194

Lengaigne M, Boulanger JP, Menkes C, Madec G, Delecluse P, Guilyardi E, Slingo JM (2003) The March 1997 westerly wind event and the onset of the 1997/98 El Niño: understanding the role of the atmospheric response. J Clim 16(20):3330-3343

Lengaigne M, Boulanger JP, Menkes C, Delecluse P, Slingo J (2004) Westerly Wind Events in the tropical Pacific and their influence on the coupled ocean-atmosphere system: a review. In: Wang C, Xie SP, Carton JA (eds) Earth's climate: the ocean-atmosphere interaction. Geophysical monograph series, vol 147. American Geophysical Union, Washington. https://doi.org/10.1029/147GM03

McPhaden MJ, Zhang X, Hendon HH, Wheeler MC (2006) Large scale dynamics and MJO forcing of ENSO variability. Geophys Res Lett 33(16):627-642

Meinen CS, McPhaden MJ (2000) Observations of warm water volume changes in the equatorial Pacific and their relationship to El Niño and La Niña. J Clim 13(20):3551-3559

Menkes CE, Lengaigne M, Vialard J, Puy M, Marchesiello P, Cravatte S, Cambon G (2014) About the role of Westerly Wind Events in the possible development of an El Niño in 2014. Geophys Res Lett 41(18):6476-6483. https://doi.org/10.1002/2014GL061186

Min Q, Su J, Zhang R, Rong X (2015) What hindered the El Niño pattern in 2014? Geophys Res Lett 42(16):6762-6770

Philander SGH, Yamagata T, Pacanowski RC (1984) Unstable air-sea interactions in the tropics. J Atmos Sci 41:604-613

Puy M, Vialard J, Lengaigne M, Guilyardi E (2016a) Modulation of equatorial Pacific westerly/easterly wind events by the MaddenJulian oscillation and convectively-coupled Rossby waves. Clim Dyn 46(7-8):2155-2178

Puy M, Vialard J, Lengaigne M, Guilyardi E, Voldoire A, Madec G (2016b) Modulation of equatorial Pacific sea surface temperature response to westerly wind events by the oceanic background state. Clim Dyn 2016:1-25

Puy M, Vialard J, Lengaigne M, Guilyardi E, Dinezio PN, Voldoire A, Balmaseda M, Madec G, Menkes C, Mcphaden MJ (2017) Influence of westerly wind events stochasticity on El Niño amplitude: the case of 2014 vs. 2015. Clim Dyn 674:1-20

Reynolds RW, Smith TM, Liu C, Chelton DB, Casey KS, Schlax MG (2007) Daily high-resolution-blended analyses for sea surface temperature. J Clim 20:5473-5496

Santoso A, Mcphaden MJ, Cai W (2017) The defining characteristics of ENSO extremes and the strong 2015/2016 El Niño. Rev Geophys 55(4):1079-1129. https://doi.org/10.1002/2017RG000560

Schopf PS, Harrison DE (1983) On equatorial waves and El Niño. I. Influence of initial states on wave-induced currents and warming. J Phys Oceanogr 13(6):936-948

Takahashi K, Dewitte B (2016) Strong and moderate nonlinear El Niño regimes. Clim Dyn 46:1627-1645. https://doi.org/10.1007/s0038 2-015-2665-3

Tziperman E, Zebiak SE, Cane MA (1997) Mechanisms of seasonal-ENSO interaction. J Atmos Sci 54:61-71. https://doi. org/10.1175/1520-0469(1997)054\%3C0061:MOSEI\%3E2.0.CO;2

Vecchi G, Harrison D (2000) Tropical Pacific sea surface temperature anomalies, El Niño, and equatorial westerly wind events. J Clim 13(11):1814-1830

Wang B, Wu R, Fu X (2000) Pacific-East Asian teleconnection: how does ENSO affect East Asian climate? J Clim 13(9):1517-1536

Wu Y, Chen L, Hong C, Li T, Chen C, Wang L (2018) Role of the meridional dipole of SSTA and associated cross-equatorial flow in the tropical eastern Pacific in terminating the 2014 El Niño development. Clim Dyn 50(5-6):1625-1638

Wyrtki K (1985) Water displacements in the Pacific and the genesis of El Niño cycles. J Geophys Res Oceans 90(C4):7129-7132

Xue Y, Cane MA, Zebiak SE, Palmer TN (1997) Predictability of a coupled model of ENSO using singular vector analysis. part I: optimal growth in seasonal background and ENSO cycles. Mon Weather Rev 125(9):2043-2056

Yang S, Li Z, Yu JY, Hu X, Dong W, He S (2018) El Niño-Southern Oscillation and its impact in the changing climate. Nat Sci Rev 5(6):840-857

Yeh S, Kug J, Dewitte B, Kwon M, Kirtman B, Jin FF (2009) El Niño in a changing climate. Nature 461(7263):511

Zebiak SE, Cane MA (1987) A model El Niño-Southern Oscillation. Mon Weather Rev 115:2262-2278

Zhang R, Gao C (2017) Processes involved in the second-year warming of the $2015 \mathrm{El}$ Niño event as derived from an intermediate ocean model. Sci China Earth Sci 60(9):1601-1613

Zhang HM, Bates JJ, Reynolds RW (2006) Assessment of composite global sampling: sea surface wind speed. Geophys Res Lett 33(17):L17714. https://doi.org/10.1029/2006gl027086

Zhu J, Kumar A (2018) Influence of surface nudging on climatological mean and ENSO feedbacks in a coupled model. Clim Dyn 50(1-2):571-586

Zhu J, Kumar A, Huang B (2015) The relationship between thermocline depth and SST anomalies in the eastern equatorial Pacific: seasonality and decadal variations. Geophys Res Lett 42(11):4507-4515

Zhu J, Kumar A, Huang B, Balmaseda MA, Hu ZZ, Marx L, Kinter JL III (2016) The role of off-equatorial surface temperature anomalies in the 2014 El Niño prediction. Sci Rep 6:19677

Publisher's Note Springer Nature remains neutral with regard to jurisdictional claims in published maps and institutional affiliations. 